Article

\title{
Exploring the Slow Magnetic Relaxation of a Family of Photoluminescent 3D Lanthanide-Organic Frameworks Based on Dicarboxylate Ligands
}

\author{
Itziar Oyarzabal 1,2®, Sara Rojas ${ }^{3}$, Ana D. Parejo ${ }^{3}$, Alfonso Salinas-Castillo $4{ }^{4}$, José Ángel García 5 , \\ José M. Seco ${ }^{6}\left(\mathbb{D}\right.$, Javier Cepeda ${ }^{6, *(\mathbb{B})}$ and Antonio Rodríguez-Diéguez ${ }^{3, *(\mathbb{D})}$
}

1 BCMaterials, Basque Center for Materials, Applications and Nanostructures, UPV/EHU Science Park, 48940 Leioa, Spain; itziar.oyarzabal@bcmaterials.net

2 IKERBASQUE, Basque Foundation for Science, 48009 Bilbao, Spain

3 Departamento de Química Inorgánica, UEQ, Facultad de Ciencias, Universidad de Granada, 18071 Granada, Spain; s.rojas@ugr.es (S.R.); anadeliapv@correo.ugr.es (A.D.P.)

4 Departamento de Química Analítica, UEQ, Facultad de Ciencias, Universidad de Granada, 18071 Granada, Spain; alfonsos@ugr.es

5 Departamento de Física Aplicada II, Facultad de Ciencia y Tecnología, Universidad del País Vasco/Euskal Herriko Unibertsitatea (UPV/EHU), 48940 Leioa, Spain; joseangel.garcia@ehu.eus

6 Departamento de Química Aplicada, Facultad de Química, Universidad del País Vasco/Euskal Herriko Unibertsitatea (UPV/EHU), 20018 Donostia, Spain; josemanuel.seco@ehu.eus

Citation: Oyarzabal, I.; Rojas, S.; Parejo, A.D.; Salinas-Castillo, A.; García, J.Á.; Seco, J.M.; Cepeda, J.; Rodríguez-Diéguez, A. Exploring the Slow Magnetic Relaxation of a Family of Photoluminescent 3D Lanthanide-Organic Frameworks Based on Dicarboxylate Ligands. Magnetochemistry 2021, 7, 41. https://doi.org/10.3390/ magnetochemistry7030041

Academic Editors: Laura Cristina de Jesus Pereira, Bernardo Monteiro and Cláudia Pereira

Received: 23 February 2021

Accepted: 12 March 2021

Published: 16 March 2021

Publisher's Note: MDPI stays neutral with regard to jurisdictional claims in published maps and institutional affiliations.

Copyright: (c) 2021 by the authors. Licensee MDPI, Basel, Switzerland. This article is an open access article distributed under the terms and conditions of the Creative Commons Attribution (CC BY) license (https:/ / creativecommons.org/licenses/by/ $4.0 /)$.

* Correspondence: javier.cepeda@ehu.es (J.C.); antonio5@ugr.es (A.R.-D.); Tel.: +34-943015409 (J.C.); +34-958248524 (A.R.-D.)

Abstract: A family of metal-organic frameworks with general formula $\left\{\left[\mathrm{Nd}_{2}(\mathrm{ant})_{2}\left(\left(\mathrm{NH}_{2}\right)_{2}\right.\right.\right.$-bdc)$\left.\left.(\mathrm{DMF})_{4}\right] \cdot 2 \mathrm{DMF}\right\}_{\mathrm{n}}(\mathbf{1})$ and $\left\{\left[\mathrm{Ln}_{2}(\mathrm{ant})_{2}\left(\left(\mathrm{NH}_{2}\right)_{2} \text {-bdc }\right)(\mathrm{DMF})_{4}\right] \cdot 2 \mathrm{DMF} \cdot 2 \mathrm{H}_{2} \mathrm{O}\right\}_{\mathrm{n}}(\mathrm{Ln}=\mathrm{Tb}(2), \mathrm{Ho}(3)$, and Er (4)) has been obtained from reactions between 9,10-anthracenedicarboxylic $\left(\mathrm{H}_{2}\right.$ ant) and 2,5diaminoterephthalic $\left(\left(\mathrm{NH}_{2}\right)_{2}-\mathrm{H}_{2} \mathrm{bdc}\right)$ acids, and lanthanide ions in dimethylformamide (DMF). These lanthanide-organic frameworks (LnOFs) have been characterized, and their crystal structures have been elucidated by single crystal and powder X-ray diffraction methods (on the basis of a comparative refinement with similar structures), respectively for $\mathbf{1}$ and $\mathbf{2}-\mathbf{4}$. All LnOFs present three-dimensional structures composed of dinuclear $\left[\mathrm{Ln}_{2}\left(\mu-\mathrm{CO}_{2}\right)_{4}\right]$ entities linked through both carboxylate ligands that yield open frameworks in which DMF and water molecules are located in the channels. Magnetic studies of these LnOFs have revealed slow relaxation of the magnetization for the Nd-based counterpart. The compounds also acknowledge relevant photoluminescence (PL) emissions in the visible (for the Tb-based homologue) and near-infrared (for the Nd- and Er-based compounds) regions. The strong green emission yielded by compound $\mathbf{2}$ at room temperature allows its study for photoluminescence (PL) sensing of various solvent molecules, finding a particular discrimination for acetone.

Keywords: lanthanide-organic frameworks; 9,10-anthracenedicarboxylate; 2,5-diaminoterephthalate; dinuclear building unit; photoluminescence; slow relaxation of magnetization; acetone sensor

\section{Introduction}

Metal-organic frameworks (MOFs) are a class of microporous crystalline materials with structural and topological features that produce very fascinating properties $[1,2]$. These compounds consist of a highly ordered and extended 3D network based on metal ions or clusters coordinated to multidentate organic molecules that act as linkers [3]. The first MOFs were formed with transition metal ions, making their structures easily predictable due to the rigid coordination spheres exhibited by these metal ions, which is an advantage when aiming to design but also limits the possible structural patterns to be acquired by ligands and detracts flexibility from the framework [4,5]. In the last decade, the interest in 
lanthanide-based MOFs, LnOFs hereafter, is rising due to their versatilities in areas such as luminescence [6,7], gas adsorption [8-11], optical storage [12,13], and magnetism [14]. The problem lies on the fact that lanthanide elements have very high and variable coordination numbers, which brings us to the issue that the coordination geometries and the LnOF topologies are difficult to control [15]. Instead, once a dominant architecture is achieved and the factors affecting the structural variability are isolated [16-18], it allows obtaining an isostructural family of lanthanide-based materials in which a comparative analysis of a specific property may be accomplished.

Among the potential properties of LnOFs, magnetism and luminescence are particularly interesting due to the shielded nature of the electrons in the $4 \mathrm{f}$ shell of these elements [19-21], which endows them with special intraionic electronic transitions that enable the occurrence of slow magnetic relaxation (SRM) and solid-state bright light emission, thus rendering materials behaving as single-molecule magnets (SMMs) [22-25] and organic light-emitting diodes (OLEDs) [26], respectively for the mentioned properties. On the one hand, the magnetic properties of these materials are being intensely studied since Mínguez-Espallargas et al. showed for the first time that an LnOF could present SMM-type behaviour due to the strong magnetic anisotropy occurring in the lanthanide ion [22,27]. As it is known, the presence of SRM below a certain temperature (called blocking temperature, $T_{B}$ ) is derived from both the large spin state of the molecule and magnetic anisotropy (usually axial, $D$, although other distributions such as plane anisotropy are also known, $E$ ). In this sense, the large magnetic moment and sizeable single-ion anisotropy derived from spin-orbit coupling (SOC) effect afforded by these ions when the nature and symmetry of their local environment is appropriate $[20,28]$ imposes significant energy barriers preventing the reversal of the magnetization in the compound [29]. On the other hand, the coordination of lanthanide(III) ions to organic ligands with appropriate chromophores, containing better light absorption capacity than lanthanide(III) ions, characterized for narrow absorption bands, brings the opportunity of generating bright, long-lived, sharp, and also efficient emissions in the LnOFs [30]. This occurrence is a consequence of the antennae effect [31,32], by which there is an energy transfer from the ligand to the lanthanide(III) ion provided that the inner levels of the metal ion remain shielded to avoid interactions generating luminescence quenching [6,33]. Additionally, it is important to note that luminescent properties of lanthanides are sensitive to changes in their coordination environment and other neighboring molecules, which is a fact that considering the open architecture of LnOFs may result in their capacity to show guest-responsive luminescence and even a specific luminescence sensing [34,35].

In previous works, we and others have constructed SMMs by using organic linkers with carboxylate groups and dysprosium ions to take advantage of their large magnetic moment and single-ion anisotropy derived from SOC and the crystal field effect $[20,22]$. In this sense, we have recently designed a new family of 3D LnOFs consisting of the 9,10-anthracenedicarboxylic linker $\left(\right.$ ant $\left.^{2-}\right)$ that exhibits a slow relaxation of magnetization [36]. In an attempt to modulate the properties of the system, we decided to introduce a second ligand possessing the ability to coordinate in a similar way to the ant ${ }^{2-}$, among which we opted for 2,5-diaminoterephthalic acid $\left(\left(\mathrm{NH}_{2}\right)_{2}\right.$-bdc) due to its aromaticity and pending amino groups, which facilitate the absorption of light and the establishment of supramolecular interactions that provide the LnOF with stability to prevent luminescence quenching (see Scheme 1) [37]. 

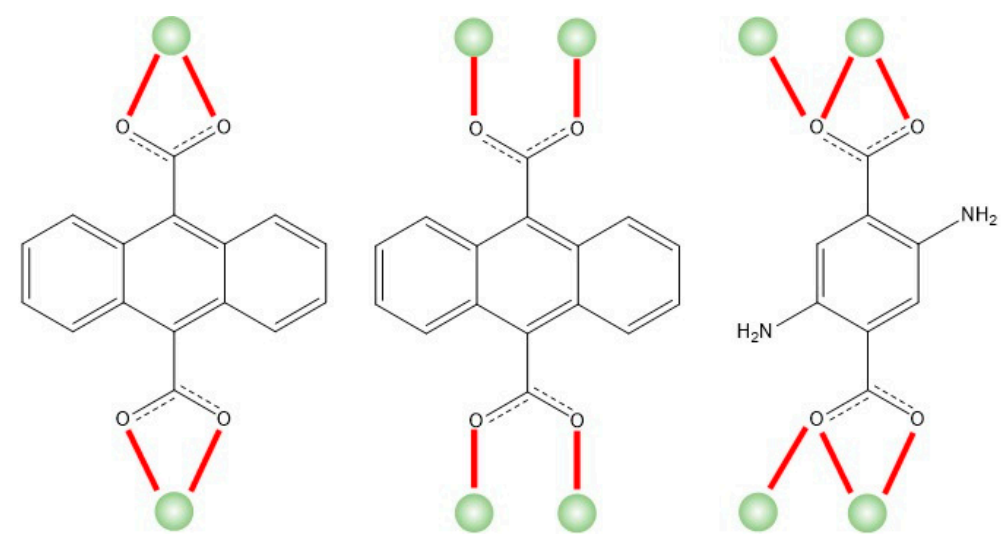

Scheme 1. Different coordination modes shown by the ligands employed to construct metal-organic frameworks (MOFs).

Following this line, we have now set out to synthesize other counterparts based on $\mathrm{ant}^{2-}$ and $\left(\mathrm{NH}_{2}\right)_{2}-\mathrm{bdc}^{2-}$ ligands, making use of different lanthanide ions to explore the effects caused by the ions sizes in the framework and in the properties of the resulting materials. In particular, we herein report on the synthesis, structure, and luminescent properties of four new 3D-MOFs of general formulae $\left\{\left[\mathrm{Nd}_{2}(\mathrm{ant})_{2}\left(\left(\mathrm{NH}_{2}\right)_{2} \text {-bdc)(DMF }\right)_{4}\right] \cdot 2 \mathrm{DMF}\right\}_{\mathrm{n}}$ (1) and $\left\{\left[\mathrm{Ln}_{2}(\mathrm{ant})_{2}\left(\left(\mathrm{NH}_{2}\right)_{2} \text {-bdc)(DMF }\right)_{4}\right] \cdot 2 \mathrm{DMF} \cdot 2 \mathrm{H}_{2} \mathrm{O}\right\}_{\mathrm{n}}(\mathrm{Ln}=\mathrm{Tb}(2), \mathrm{Ho}(3)$, and $\mathrm{Er}(4))$. The magnetic properties have been analyzed by measuring variable temperature direct and alternating ( $d c$ and $a c$, respectively) susceptibility in order to evaluate both the isolation of spin carriers in the framework, aided by computational calculations, and lanthanide ions and their dynamics occurring in the relaxation. Moreover, with the aim to establish their potential multifunctional character, the emissive properties have been analyzed in solid state under variable temperatures and, in view of the porous nature of the compounds, also in response to different solvents, seeking a potential sensor activity of the LnOFs.

\section{Results and Discussion}

\subsection{General Comments on the Synthesis}

The solvothermal reactions of two different dicarboxylate ligands with different lanthanide salts in dimethylformamide $(4 \mathrm{~mL})$ at $95^{\circ} \mathrm{C}$ for $24 \mathrm{~h}$ produced prismatic crystals and powder of four different 3D LnOFs. The crystal structure of the compound $\mathbf{1}$ was determined using single crystal $X$-ray diffraction. Although we were not able to obtain single crystals from the rest of compounds $(2,3$, and 4$)$, powder X-ray diffraction (PXRD) data of these compounds corroborated that the materials are isostructural to a previously reported dysprosium-based MOF [37] (Figure S1). Despite the fact that no significant differences were applied during the synthesis of these materials, two structurally similar compounds are obtained according to their chemical formulae, which only differ in the content of the solvent molecules crystallized in the voids, which is a fact that is in turn derived from the slight differences occurring in the framework. As it will be detailed in the structural descriptions during the next sections, the structural and chemical discrepancy of these LnOFs may be only attributed to the ion size of the lanthanide(III) ion used. It is well known that lanthanide(III) ions present a very similar reactivity with most of the ligands, despite which they may render isostructural or different compounds depending on the flexibility of the resulting crystal structure. In this sense, there are structures admitting most of the lanthanide(III) ions of the series, as observed for the isostructural family of homometallic $\left\{\left[\mathrm{Ln}_{2}\left(\mu_{4} \text {-pmdc }\right)_{2}(\mu-\mathrm{pmdc})\left(\mathrm{H}_{2} \mathrm{O}\right)_{2}\right] \cdot \mathrm{H}_{2} \mathrm{O}\right\}_{\mathrm{n}}$ compounds $(\mathrm{Ln}=\mathrm{La}-\mathrm{Yb}$, pmdc $=$ pyrimidine-4,-dicarboxylate) [38] or heterometallic $\left[\mathrm{Zn}(\mu-\mathrm{L})(\mu-\mathrm{OAc}) \mathrm{Ln}\left(\mathrm{NO}_{3}\right)_{2}\right]$ complexes $\left(\mathrm{Ln}=\mathrm{Pr}-\mathrm{Yb}, \mathrm{H}_{2} \mathrm{~L}=\mathrm{N}, N^{\prime}\right.$-dimethyl- $N, N^{\prime}$-bis(2-hydroxy-3-methoxy-5-methylbenzyl)ethylenediamine) [39]. Instead, the slight change of ion size occurring between two contiguous lanthanides is enough to force the crystallization of completely different structures in other cases, such as the case of the compounds of $\left\{\left[\mathrm{Ce}\left(\mu_{4} \text {-pzdc }\right)\left(\mathrm{NO}_{3}\right)\left(\mathrm{H}_{2} \mathrm{O}\right)_{2}\right] \cdot 2.33 \mathrm{H}_{2} \mathrm{O}\right\}_{\mathrm{n}}$ 
and $\left\{\left[\mathrm{Pr}_{9}\left(\mu_{4} \text {-pzdc }\right)_{9}\left(\mathrm{NO}_{3}\right)_{2}\left(\mathrm{H}_{2} \mathrm{O}\right)_{25}\right]\left(\mathrm{NO}_{3}\right)_{7} \cdot 8 \mathrm{H}_{2} \mathrm{O}\right\}_{n}$ formulae obtained with pyrazine-2,5dicarboxylate (pzdc) ligand [40]. The present case falls within the second (more common) casuistry, since the change in the ion size between $\mathrm{Nd}$ (III) and the group of $\mathrm{Tb}(\mathrm{III}), \mathrm{Ho}(\mathrm{III})$, and $\operatorname{Er}$ (III) (framed respectively between the first and second halves of the lanthanide series) seems to be the main responsible for the observed structural variability.

\subsection{Structural Description of Compound $\left\{\left[\mathrm{Nd}_{2}(\text { ant })_{2}\left(\left(\mathrm{NH}_{2}\right)_{2}-\mathrm{bdc}\right)(\mathrm{DMF})_{4}\right] \cdot 2 \mathrm{DMF}\right\}_{n}$ (1)}

Compound 1 crystallizes in the triclinic space group $P-1$. The asymmetric unit contains one $\mathrm{Nd}(\mathrm{III})$ atom, two halves of ant ${ }^{2-}$ ligands, half a $\left(\mathrm{NH}_{2}\right)_{2}-\mathrm{bdc}^{2-}$ ligand, and two coordination DMF molecules. The $\mathrm{Nd}(\mathrm{III})$ atom has a $\mathrm{NdO}_{9}$ coordination environment formed by its coordination to five oxygen atoms pertaining to three different ant ${ }^{2-}$, two oxygen atoms belonging to two $\left(\mathrm{NH}_{2}\right)_{2}-\mathrm{bdc}^{2-}$ ligands, and two oxygen atoms of two DMF coordinated molecules. The continuous shape measures (CShMs) calculated by the SHAPE program [41] reveal that the polyhedron may be best described as a muffin (Table S1). The $\mathrm{Nd}-\mathrm{O}_{\text {carb }}$ bond distances are in the range 2.417(5)-2.704(6) $\AA$, whereas the $\mathrm{Nd}-\mathrm{O}_{\mathrm{DMF}}$ distances are 2.447(6) and 2.458(5) A (see Table 1 for more detail).

Table 1. Selected bond lengths (§) for compound 1 [a].

\begin{tabular}{cccc}
\hline Nd1-O1A & $2.417(5)$ & Nd1-O1C(i) & $2.704(6)$ \\
Nd1-O2A(i) & $2.442(5)$ & Nd1-O2C(i) & $2.486(6)$ \\
Nd1-O1B & $2.518(6)$ & Nd1-O1M & $2.458(5)$ \\
Nd1-O2B & $2.492(6)$ & Nd1-O1N & $2.447(6)$ \\
Nd1-O1C & $2.446(5)$ & - & - \\
\hline
\end{tabular}

[a] Symmetry code: (i) $-x+1,-y+1,-z+1$.

Two of the ant ${ }^{2-}$ ligands and the two $\left(\mathrm{NH}_{2}\right)_{2}-\mathrm{bdc}^{2-}$ ligands establish paddle-wheelshaped dimeric entities by coordinating two symmetry related $\mathrm{Nd}(\mathrm{III})$ ions by means of their carboxylate groups, in such a way that both ligands are alternately linked each ca. $90^{\circ}$ from each other (Figure 1 ). It must be noticed that the two carboxylate ligands do not show the same bridging mode because the $\mathrm{ant}^{2-}$ ligands display a $\mu-\kappa \mathrm{O}: \mathrm{KO}^{\prime}$ local mode, whereas the two $\left(\mathrm{NH}_{2}\right)_{2}-\mathrm{bdc}^{2-}$ bridges by $\mu-\kappa^{2} \mathrm{O}, \mathrm{O}^{\prime}: \mathrm{KO}$ mode impose an $\mathrm{Nd} \cdots \mathrm{Nd}$ distance of $4.150 \AA$ (Figure 1 ).

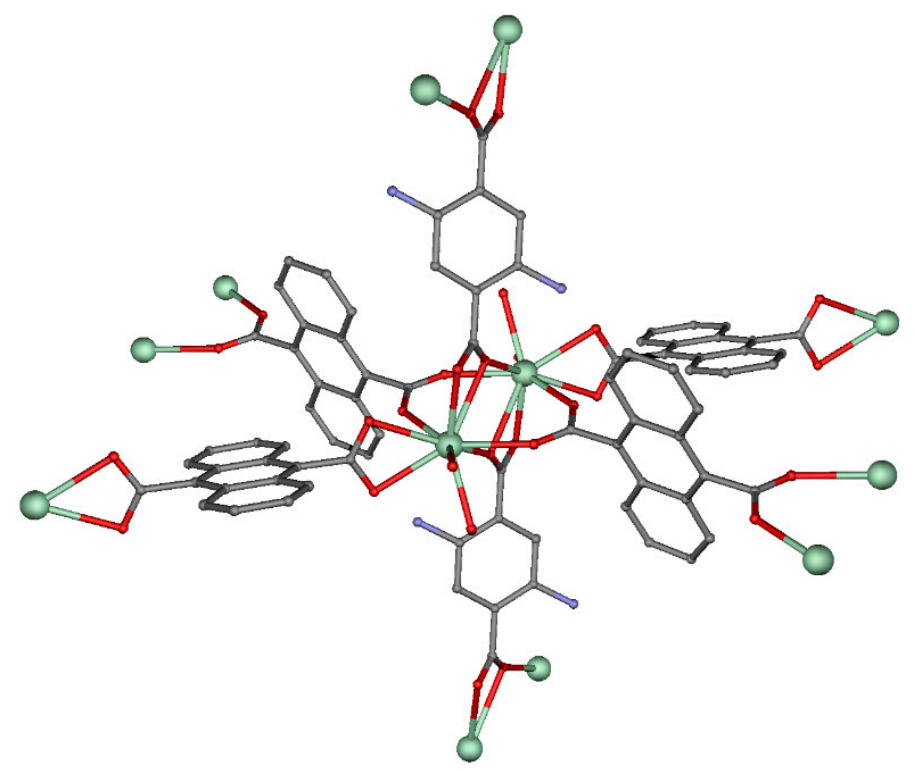

Figure 1. Dinuclear entity formed by two dysprosium atoms, four ant ${ }^{2-}$ ligands, two 2,5diaminoterephthalic linkers, and four dimethylformamide (DMF) coordination molecules. Hydrogen atoms have been omitted for clarity. $\mathrm{N}=$ blue, $\mathrm{O}=$ red, $\mathrm{C}=$ gray, $\mathrm{Nd}=$ green. 
The 3D-MOF is built by further links formed by the aforementioned two ligands, given that they show equivalent coordination patterns at the other carboxylate group as a consequence of their centrosymmetric nature. In addition to these bridging modes, each $\mathrm{Nd}$ (III) atom is also coordinated to another ant ${ }^{2-}$ linker that forms a chelating ring as a consequence of the $\mathrm{k}^{2} \mathrm{O}, \mathrm{O}^{\prime}$ mode, which bridges the dinuclear entities to one another. If we consider these dinuclear units as building blocks, we could say that they propagate the structure, acting as a six-connected node in which the bis(bridging) ligands somehow simulate the struts of an octahedron. All in all, the junction of the dinuclear units generates a three-dimensional network that, making use of the TOPOS program [42,43], may be successfully described by the $\left(4^{12} \cdot 6^{3}\right)$ point symbol, taking into account that it belongs to the pcu (primitive cubic) topological class. The resulting open framework leaves isolated voids that are well guessed along the crystallographic $c$ axis of the structure to which the amino groups from 2,5-diaminoterephthalic linkers and coordinated DMF molecules are oriented (Figure 2). Although the lattice molecules could not be solved due to the large disorder present, it was concluded that there were dimethylformamide (DMF) molecules occupying those voids according to the analysis performed with the PLATON program (see Section S3 in the ESI).

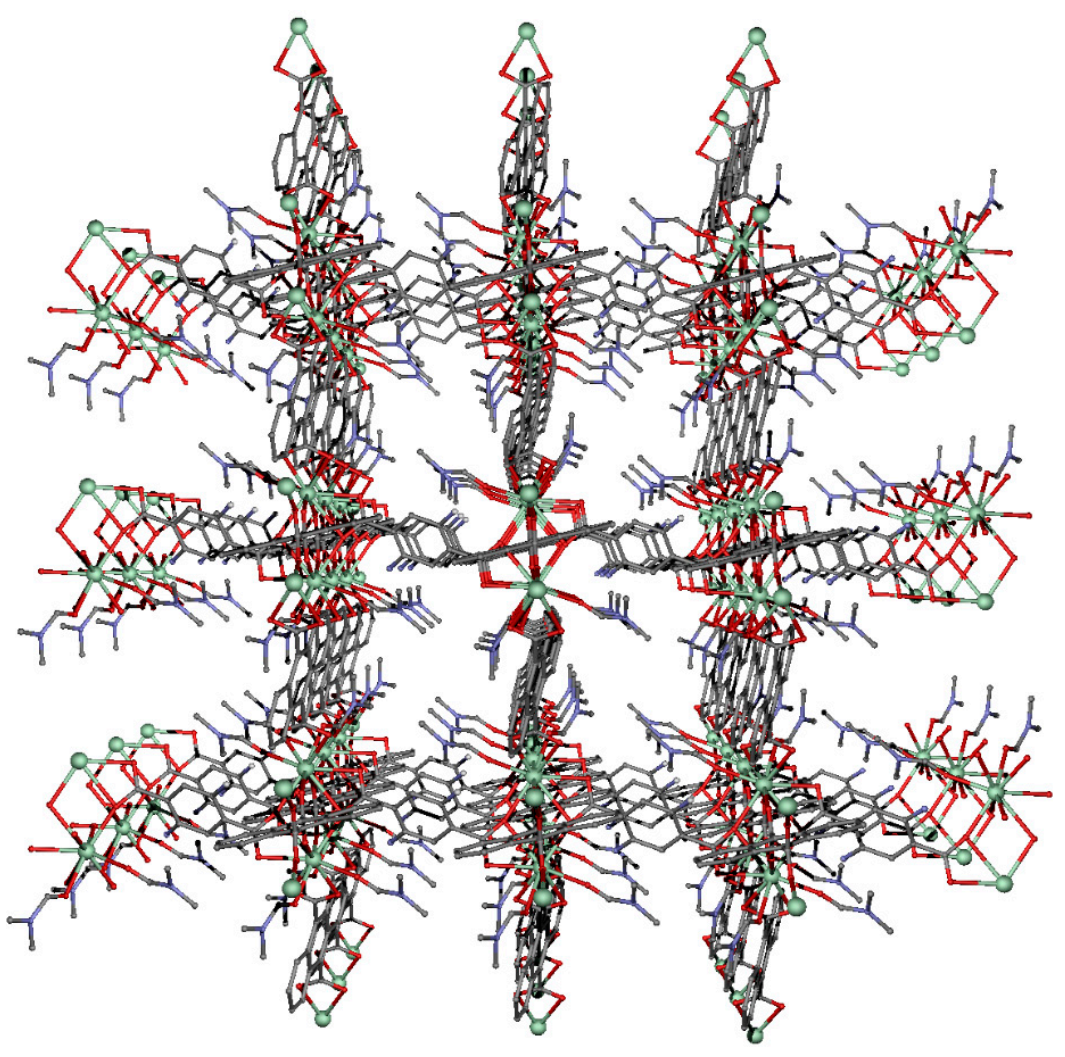

Figure 2. View along the $c$-axis of the channels in compound 1. DMF solvent molecules and hydrogen atoms have been omitted for clarity.

2.3. Structural Description of Compounds $\left\{\left[\mathrm{Ln}_{2}(\mathrm{ant})_{2}\left(\left(\mathrm{NH}_{2}\right)_{2}-b d c\right)(\mathrm{DMF})_{4}\right] \cdot 2 \mathrm{DMF} \cdot 2 \mathrm{H}_{2} \mathrm{O}\right\}_{n}$ $(\mathrm{Ln}=\mathrm{Tb}(2), \mathrm{Ho}(3)$ and $\mathrm{Er}(4))$

These three MOFs crystallize in the triclinic space group $P-1$ and their structures, being isostructural to the previously reported Dy-based counterpart [37], are quite similar to that of compound 1, as briefly detailed in this paragraph. The first substantial difference in compounds 2-4 corresponds to the lower coordination number of the symmetrically independent lanthanide(III) ion, which shows a biaugmented trigonal prism geometry when coordinating to the same number of ligands, which is a typical polyhedron found in many previously reported lanthanide(III)-carboxylate based MOFs and coordination polymers (CPs) [44]. Hereafter, the 3D framework is also composed of lanthanide dimers 
connected by carboxylate groups of two $\mathrm{ant}^{2-}$ and $\left(\mathrm{NH}_{2}\right)_{2}-\mathrm{bdc}^{2-}$ linkers that show a bis-bridging intradinuclear coordination mode. Conversely to the dimeric entity described in compound 1 , the $\left(\mathrm{NH}_{2}\right)_{2}-\mathrm{bdc}^{2-}$ ligand does not show a $\mu-\kappa^{2} \mathrm{O}, \mathrm{O}^{\prime}: \kappa \mathrm{O}$ coordination mode, but the same regular bridging $\mu-\kappa \mathrm{O}: \mathrm{kO}^{\prime}$ mode also shown by ant ${ }^{2-}$ ligands, in such a way that the resulting dimer shares the paddle-wheel shape. As earlier discussed in this work, this difference seems to be a direct consequence of the ion size of the lanthanide(III) ion, although some other factors such as the twisting of the carboxylate ligands (i.e., the out-of-plane arrangements of the carboxylate groups with respect to the aromatic rings) are slightly different, too $\left(\left(\mathrm{NH}_{2}\right)_{2}-\mathrm{bdc}^{2-}\right.$ presents an almost planar arrangement for $2-4$, but it displays a rotation of the carboxylate of $49.8^{\circ}$ ), which may be taken as a consequence thereof (Figure 3). In any case, these subtle differences occurring in the framework do not modify the connectivity, and hence, equivalent networks are obtained in terms of the topology. Nonetheless, these changes do modify the available voids left in the structure given that the solvent accessible areas, being somewhat interconnected in this case, lead to microchannels in which not only DMF but also water molecules are trapped, as reflected in their formulae.

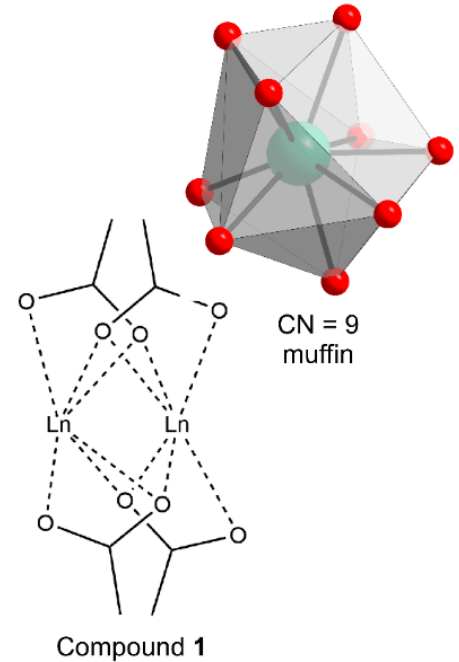

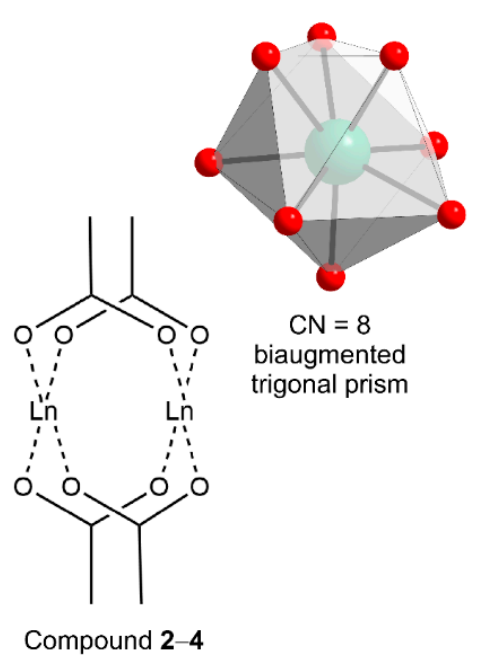

Compound 2-4

Figure 3. Schematic view of the paddle-wheel shaped cluster conforming the framework of each of the compounds.

\section{Magnetic Properties}

\subsection{Magnetic Properties}

The variable-temperature measurements of the molar magnetic susceptibility $\left(\chi_{M}\right)$ of compounds 1-4 were acquired on polycrystalline samples in the 2-300 K range (Figure 4). The $\chi_{M} T$ values obtained at room temperature are very close to those expected for the free ions ( $\mathrm{Nd}(\mathrm{III}), \mathrm{Tb}(\mathrm{III}), \mathrm{Er}(\mathrm{III})$, and $\mathrm{Ho}(\mathrm{III})$ respectively for 1, 2, 3, and 4) considering a regular population of the Stark sublevels in their ground states [45]. The progressive drop of the $\chi_{M} T$ product observed upon cooling the samples is mainly attributed to the depopulation of the high-lying $M_{J}$ sublevels of the corresponding ground terms $\left({ }^{4} \mathrm{I}_{9 / 2},{ }^{7} \mathrm{~F}_{6},{ }^{5} \mathrm{I}_{8}\right.$, and ${ }^{4} \mathrm{I}_{15 / 2}$ respectively for $\mathrm{Nd}(\mathrm{III}), \mathrm{Tb}(\mathrm{III}), \mathrm{Er}(\mathrm{III})$, and $\mathrm{Ho}(\mathrm{III})$ ) which, being quite isolated from the excited states (usually at energies $<2000 \mathrm{~cm}^{-1}$ ), are split by crystal-field effects and possibly intermolecular dipolar interactions. However, the sharp drops of the $\chi_{M} T$ product occurring for the low temperature ranges (below $50 \mathrm{~K}$ ) in most of the compounds (except for compound 1), although mainly attributed to the magnetic anisotropy present in the ions, make that the existence of a net non-zero antiferromagnetic exchange interactions may not be fully discarded in view of the relatively short carboxylate mediated Ln $\cdots$ Ln bridges of ca. $4.2 \AA$ present within the dimeric cores. 

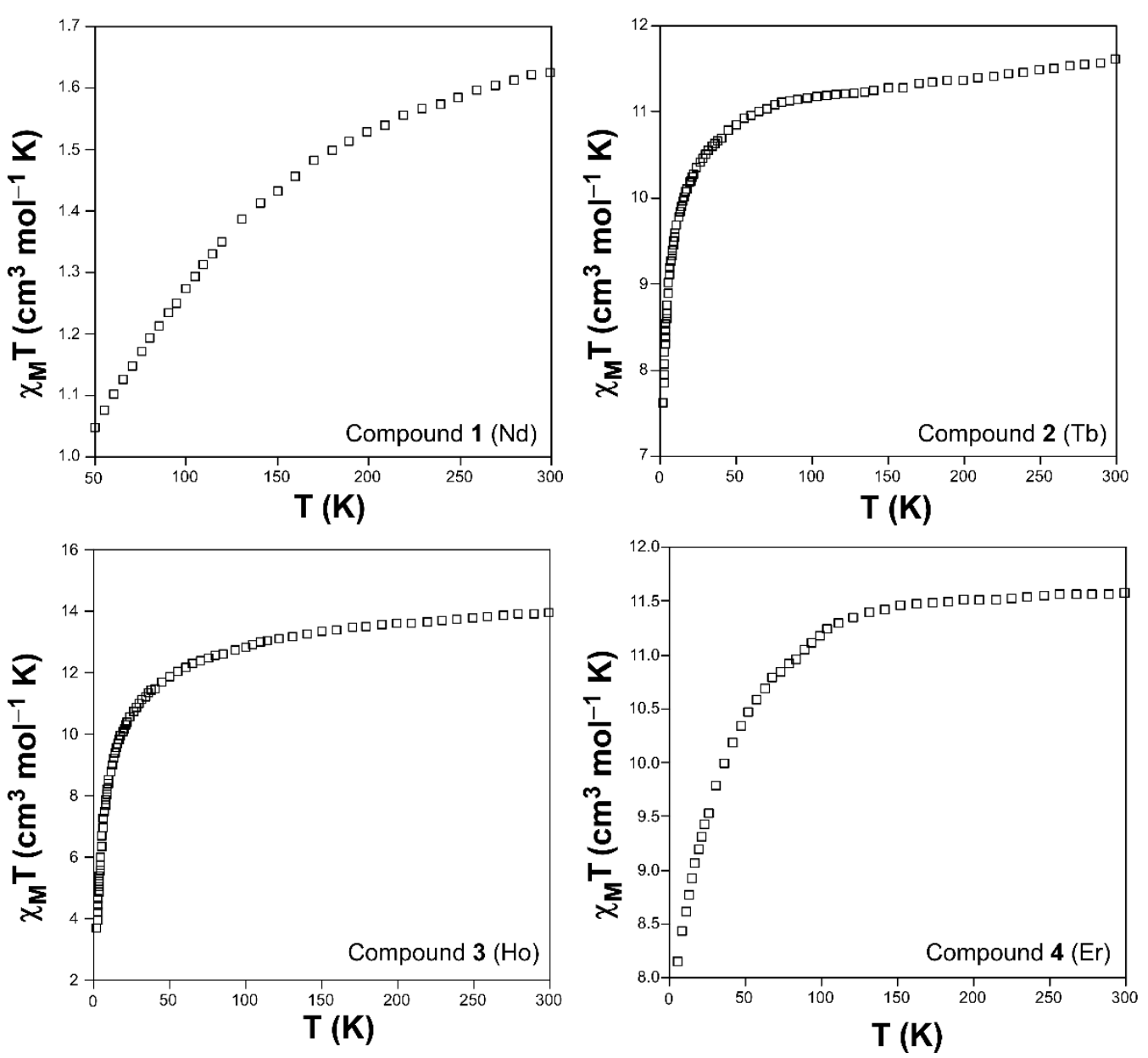

Figure 4. $\chi_{M} T$ vs. $T$ plots for all compounds. Codes for each curve are displayed as an inset.

The absence of an appropriate model that fully considers all the above-mentioned effects present in these ions by fitting the temperature-dependent susceptibility did not allow us to estimate a reliable value of the magnetic coupling constant. In order to evaluate the presence or absence of the potential exchange interactions, density-functional theory (DFT) calculations with the broken symmetry approach were performed on appropriate dimeric models based on the dimeric cores of the two distinct frameworks of compounds 1 and 2-4. These models consisted of the isostructural Gd-based counterparts grown from the X-ray coordinates of $\mathbf{1}$ and $\mathbf{2 - 4}$, given that Gd(III) ions are characterized by a ground ${ }^{8} \mathrm{~S}_{7 / 2}$ term with no orbital contribution, which allows excluding the SOC and thus estimating the exchange interactions.

As inferred from Figure 5, the calculated $J$ values, yet very low in both cases, are of opposite signs. In particular, the ferromagnetic coupling occurring in compound $\mathbf{1}$ is somewhat unexpected in view of the shape of the susceptibility measurements, which inspired us to further explore the origin of such interaction by further analyzing each of the bridges $\left(\mu-\left(\mathrm{NH}_{2}\right)_{2}\right.$-bdc- ${ }^{2} \mathrm{O}, \mathrm{O}^{\prime}: \mathrm{kO}$ and $\mu$-ant- $\left.\mathrm{KO}: \mathrm{KO}^{\prime}\right)$ coexisting in this compound. In this line, two additional calculations with the same methodology upon models in which one of each bridges was suppressed (by modeling terminal water molecules instead of carboxylate groups) allowed us to conclude that both bridges transmit antiferromagnetic interactions of a similar strength $\left(\mu-\left(\mathrm{NH}_{2}\right)_{2}\right.$-bdc and $\mu$-ant generate $J$ values of -0.002 and $-0.009 \mathrm{~cm}^{-1}$ ). The occurrence of a net ferromagnetic exchange resulting from the coexistence of two distinct bridges that individually evoke antiferromagnetic interactions is a largely reported effect, mainly for paddle-wheel dimeric entities, which is known as orbital countercomplementarity [46-49]. As detailed in these previous works, as a consequence of the different interaction between the highly occupied molecular orbitals (HOMOs) of 
each of the bridging ligands, $\left(\mathrm{NH}_{2}\right)_{2}-\mathrm{bdc}^{2-}$ and $\left(\mathrm{NH}_{2}\right)_{2}-\mathrm{bdc}^{2-}$ in the present case, with the symmetric and antisymmetric combinations of the magnetic orbitals, and provided that the interaction is weak, the antiferromagnetic contribution of the exchange may be so small that the ferromagnetic contribution takes the lead. In any case, it must be highlighted that the value of the coupling constant is too low as to expect that the magnetic exchange could eventually have a significant weight on the overall behavior, dominated by the SOC, in such a way that the lanthanide(III) ions are to be considered as practically isolated in the 3D framework.

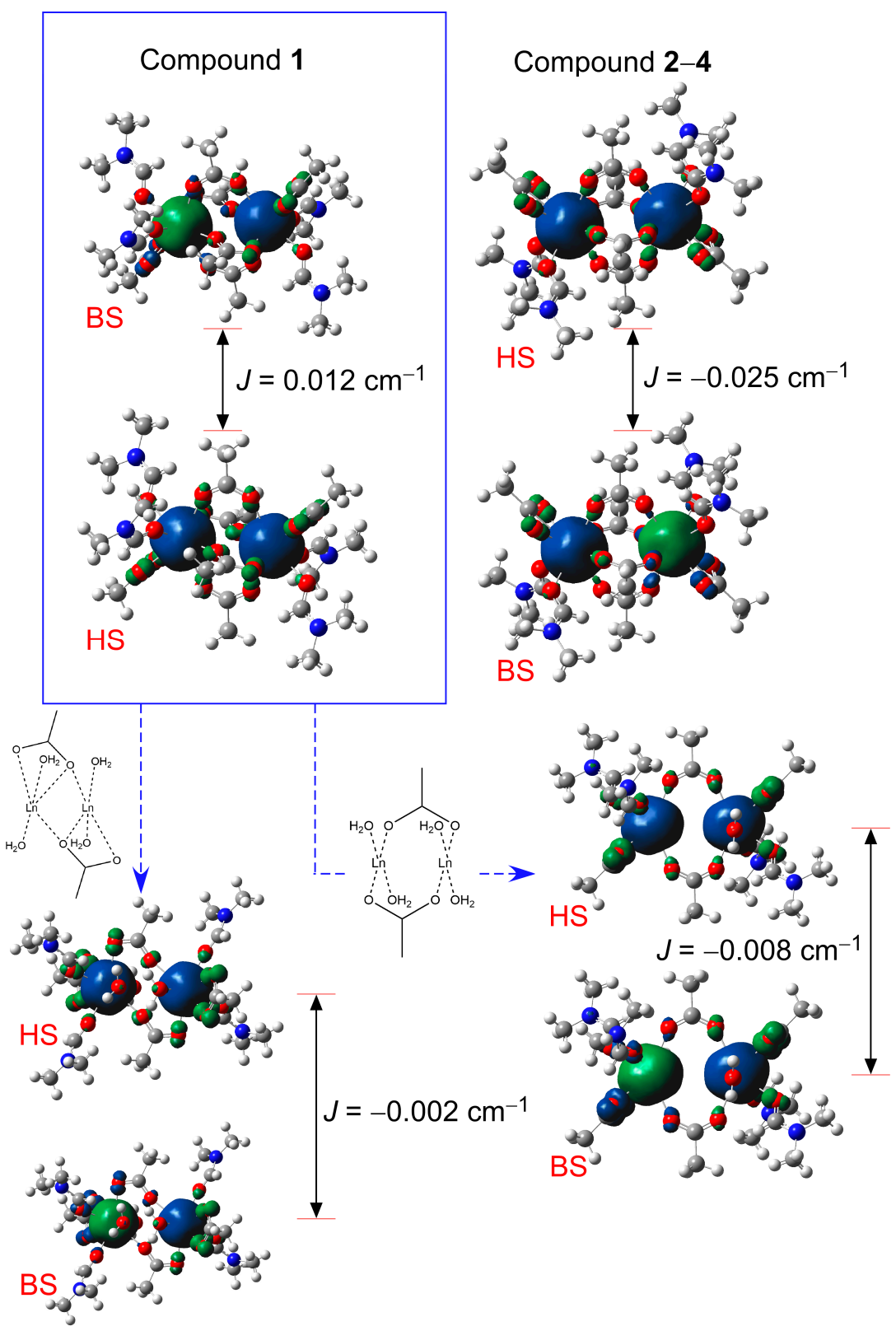

Figure 5. DFT-computed dimeric models cut from X-ray structures of compounds 1 (top left) and 2-4 (top right). The superexchange bridges conforming the paddle-wheel shaped entity of $\mathbf{1}$ are individually analyzed.

\subsection{Ac Magnetic Properties}

Dynamic ac magnetic susceptibility measurements on 1-4 reveal the absence of slow relaxation of the magnetization under the zero external $d c$ field, which is in agreement with the behavior observed for the ant ${ }^{2-}$ analogues [36]. Interestingly, the application of an external magnetic field of 1000 Oe leads to frequency dependent out-of-phase $\chi_{\mathrm{M}}{ }^{\prime \prime}$ 
signals for the $\mathrm{Nd}(\mathbf{1})$ and $\mathrm{Er}(4)$ counterparts, which is ascribed to the suppression of the quantum tunnelling (QTM) relaxation pathway. Even though 4 does not display any maxima in the $\chi_{\mathrm{M}}{ }^{\prime \prime}$ vs. T plots, 1 exhibits some well-differentiated signals below $7 \mathrm{~K}$ (Figure 6 and Figure S6). The low energy barrier $\left(U_{\text {eff }}=11.4 \mathrm{~K} ; \tau_{0}=9.4 \cdot 10^{-7} \mathrm{~s}\right)$, together with the deviation from linearity of the relaxation times at low temperatures and the fitting of the Cole-Cole plots to the generalized Debye model for $\mathbf{1}(\alpha=0.09(2 \mathrm{~K})-0.04(3.8 \mathrm{~K})$, Figure S7), suggest that the relaxation of the magnetization is not the result of an Orbach process [50]. In fact, other mechanisms such as direct or Raman could be responsible for the observed behavior, but the available data (in the $2-6 \mathrm{~K}$ range) do not allow us to unequivocally assign the origin of the relaxation process.
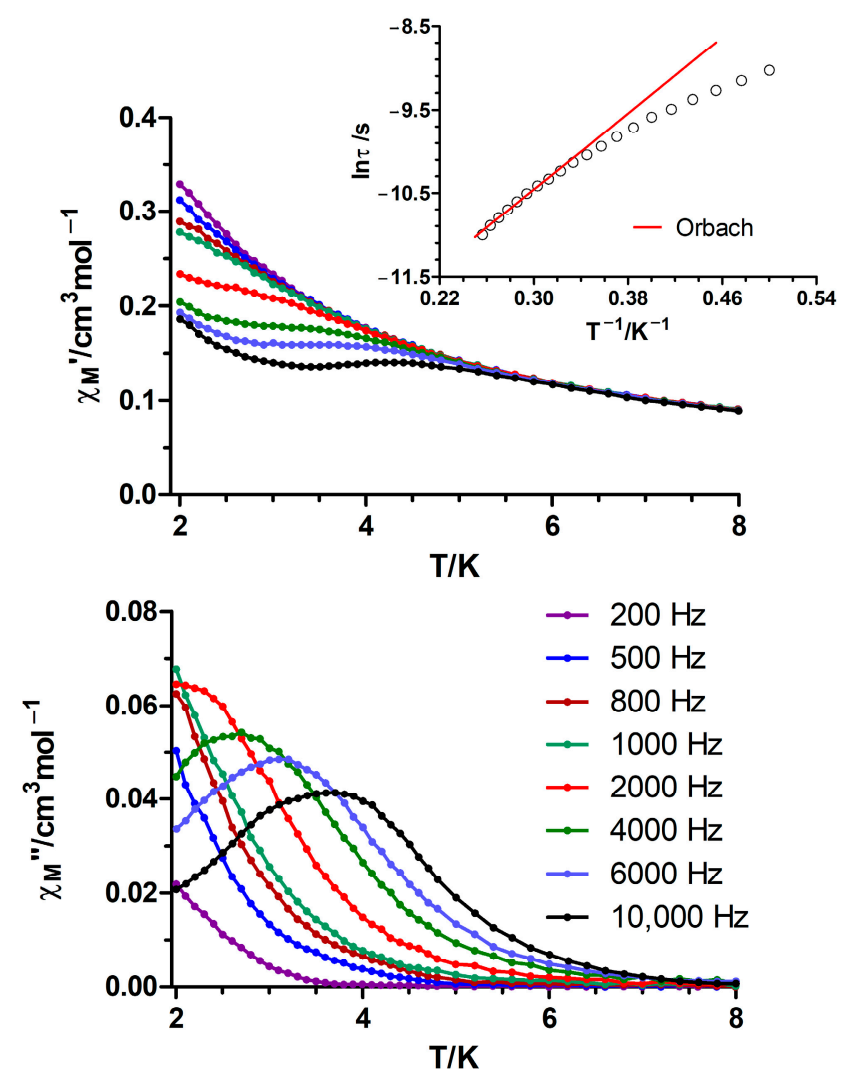

Figure 6. Temperature dependence of the in-phase (top) and out-of-phase (bottom) components of the ac susceptibility for $\mathbf{1}$ under an external field of 1000 Oe (the susceptibility values are given per $\mathrm{Nd}(\mathrm{III})$ ion). Inset: fitting of the relaxation times at each temperature (black circles) to Orbach relaxation modes (red line).

At first sight, the occurrence of clear SMR only for compound 1 and not for the rest of the compounds may be attributed to their slightly different structures and related magnetic interactions involved in the compounds, as detailed in the previous section, as well as to the Kramers nature of the $\mathrm{Nd}(\mathrm{III})$ ion [51]. On another level, a direct comparison between the compounds reported in the present work (based on ant ${ }^{2-}$ and $\left(\mathrm{NH}_{2}\right)_{2}-$ bdc $^{2-}$ ligands) and the ant ${ }^{2-}$-based compounds reveals a worsening of the magnetic properties upon the incorporation of the second ligand. In fact, $\left\{\left[\mathrm{Dy}(\mathrm{ant})_{1.5}(\mathrm{DMF})_{2}\right] \cdot(\mathrm{DMF})\right\}_{\mathrm{n}}$ and $\left\{\left[\operatorname{Er}(\mathrm{ant})_{1.5}(\mathrm{DMF})_{2}\right] \cdot(\mathrm{DMF})\right\}_{\mathrm{n}}$ exhibit slow relaxation of the magnetization with energy barriers of 52.7 and $13 \mathrm{~K}\left(H_{\mathrm{dc}}=1000 \mathrm{Oe}\right)$, respectively, while only slight frequency dependent $\chi_{M}$ " signals are observed for the $\left(\mathrm{NH}_{2}\right)_{2}-\mathrm{bdc}^{2-}$ containing materials [36,37]. Additionally, 1 displays maxima in the $\chi_{\mathrm{M}}{ }^{\prime \prime}$ vs. T plots at lower temperatures than $\left\{\left[\mathrm{Nd}(\mathrm{ant})_{1.5}(\mathrm{DMF})_{2}\right] \cdot(\mathrm{DMF})\right\}_{\mathrm{n}}$ in the same experimental conditions [36]. A careful examination of the crystal structures reveals that the $\left\{\left[\operatorname{Ln}(\mathrm{ant})_{1.5}(\mathrm{DMF})_{2}\right] \cdot(\mathrm{DMF})\right\}_{\mathrm{n}}(\mathrm{Ln}=\mathrm{Dy}$, $\mathrm{Er}, \mathrm{Nd}$ ) compounds contain $\mathrm{LnO}_{9}$ coordination spheres that are close to the muffin ideal 
geometry [52,53], as in the herein described compound $\mathbf{1}$ (Table S1), whereas the ant ${ }^{2-}$ and $\left(\mathrm{NH}_{2}\right)_{2}-\mathrm{bdc}^{2-}$-based MOFs obtained with the rest of smaller lanthanides(III) display $\mathrm{LnO}_{8}$ $(\mathrm{Ln}=\mathrm{Dy}, \mathrm{Er}, \mathrm{Tb}, \mathrm{Ho})$ polyhedra resembling biaugmented trigonal prisms. Even though both geometries can lead to the appearance of slow relaxation of magnetization [54], an unfavorable distribution of the negatively charged atoms around the lanthanide ions could explain the magnetic properties of $\mathbf{2} \mathbf{- 4}$ and the Dy analogue [55]. Additionally, the longer $\mathrm{Ln} \cdots \mathrm{Ln}$ intradinuclear distances found in the $\left(\mathrm{NH}_{2}\right)_{2}-\mathrm{bdc}^{2-}$ containing MOFs could also have a negative impact, as previously reported by our group [36]. Finally, the differences between compound 1 and $\left\{\left[\mathrm{Nd}(\mathrm{ant})_{1.5}(\mathrm{DMF})_{2}\right] \cdot(\mathrm{DMF})\right\}_{\mathrm{n}}$ can be ascribed to a slightly higher deviation from the ideal muffin geometry in $\mathbf{1}$, as supported by SHAPE measurements (Table S1).

\section{Photoluminescence Properties}

Photoluminescence measurements were carried out on polycrystalline samples of all compounds given that lanthanide-based emissions, characterized by narrow signals in the visible and near-infrared (NIR) regions [7,19], are largely desirable and useful in areas such as solid state lighting (in development devices with high quantum yields) [56-59] and biomedicine (in generating easily detectable fluoroimmunoassays) $[60,61]$. Unfortunately, these compounds did not show remarkable emission at room temperature but for the terbium-based compound 2. Under a UV excitation monochromated light of $\lambda_{\mathrm{ex}}=325 \mathrm{~nm}$, compound 2 shows six groups of signals assigned to both the ligand-based and terbiumcentred emissions (Figure 7). The first wide band peaking at ca. $450 \mathrm{~nm}$ corresponds to the $\pi \leftarrow \pi^{*}$ transitions occurring in the aromatic rings of both ant ${ }^{2-}$ and $\left(\mathrm{NH}_{2}\right)_{2}-$ bdc $^{2-}$ linkers, which is in good agreement with assignations done for related compounds [37]. Instead, the rest of the narrow bands correspond to the characteristic transitions occurring in the inner $f$ orbitals of the $\mathrm{Tb}$ (III) ion [62]. Monitoring the main emission band peaking at $\lambda_{\mathrm{em}}=548 \mathrm{~nm}$ (assigned to ${ }^{5} \mathrm{D}_{4} \rightarrow{ }^{7} \mathrm{~F}_{5}$ intraionic transition) reveals that the Tb-based emission observed in this compound comes from the ligand excitation, thus confirming the occurrence of a substantial antenna effect (see Figure S8). When the sample is cooled down to $10 \mathrm{~K}$, the metal-organic systems save much vibrational quenching related with the thermal energy of the bond electrons [63-65], which brings a substantial enhancement of the radiative signal in all cases. Particularly for compound 2, the low-temperature spectrum reveals a similar pattern, with ${ }^{5} \mathrm{D}_{4} \rightarrow{ }^{7} \mathrm{~F}_{5}$ being kept as the dominant band, except for the absence of the first band that is attributed to ligand-centred (LC) transitions. This fact confirms that the antennae effect, i.e., electronic transition occurring from the excited (LC) triplet states of the compound to the empty excited states centred on $\mathrm{Tb}(\mathrm{III})$, is much more efficient at low temperature, in such a way that absorbed light is more easily transferred to the ${ }^{5} \mathrm{D}_{4}$ state to provide ${ }^{5} \mathrm{D}_{4} \rightarrow{ }^{7} \mathrm{~F}_{J}$ transitions, thus preventing the LC emission. The dominant transitions occurring in the visible spectra confer this sample a pale-green emitted light (see inset in Figure 7).

To get deeper insights into the luminescence of this compound, the decay curve was measured in the same experimental conditions $\left(\lambda_{\mathrm{ex}}=325\right.$ and $\left.\lambda_{\mathrm{em}}=548 \mathrm{~nm}\right)$. As observed in Figure S9 in the electronic supporting information (ESI) file, the rectilinear shape of the curve reveals a monoexponential nature that allows fitting the data to Equation (1) considering a unique radiative component in agreement with the presence of only one crystallographically independent $\mathrm{Tb}$ atom.

$$
I_{t}=A_{0}+A_{1} \exp \left(-t / \tau_{1}\right)
$$



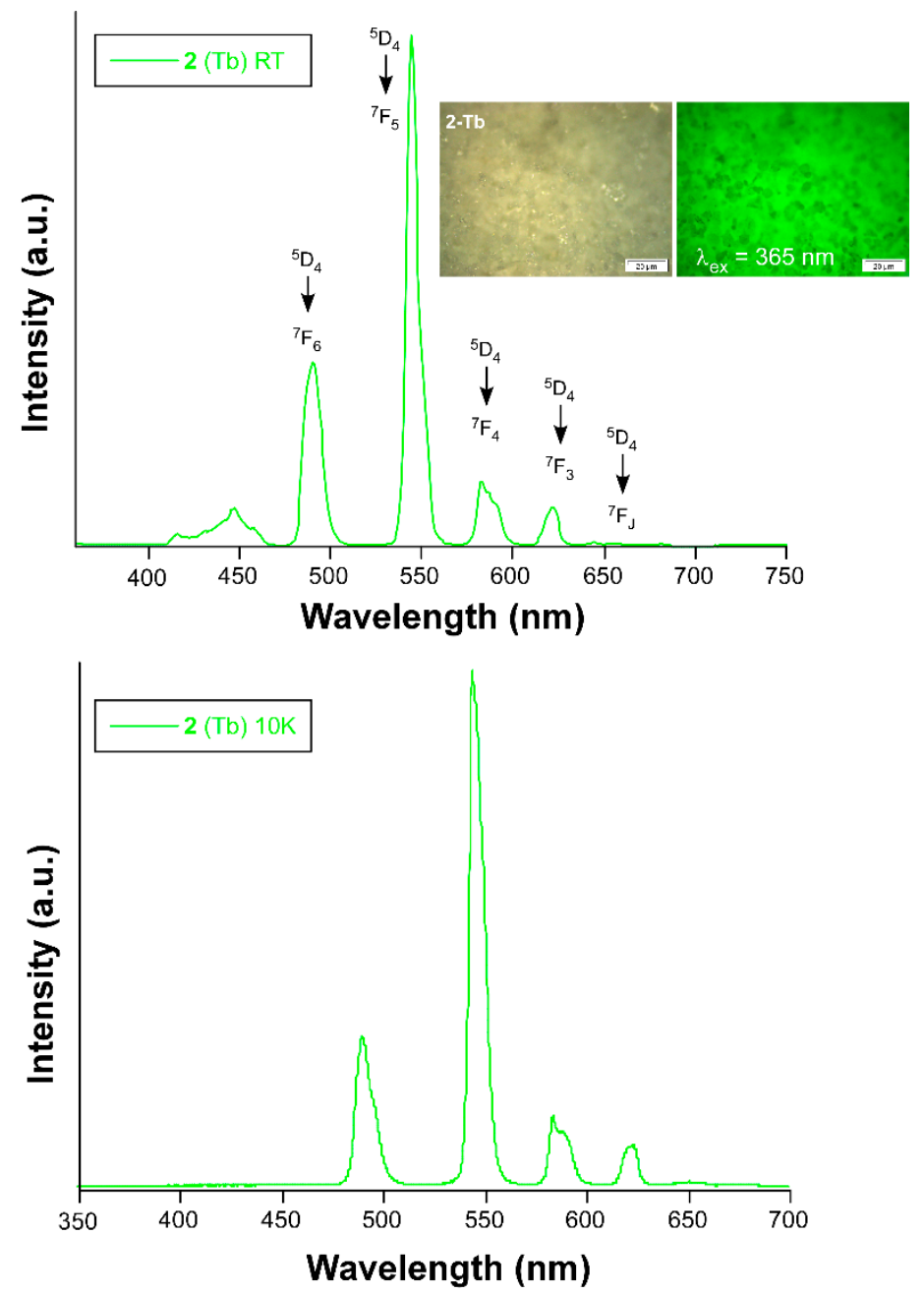

Figure 7. Emission spectra of compound 2 recorded at room (top) and low temperature (bottom).

Best fitting of the curve gives a lifetime of $980 \mu$ s, which is a relatively large value rounding the range of one millisecond and thus, it is close to the long persistent phosphorescence phenomenon, which is a highly desirable property exploitable for developing light-emitting diodes, flat-panel displays, photo-stimulable storage screens, fiber-optic thermometers, and so on $[26,66]$. This long lifetime is also indicative of an efficient shielding of the metal toward a non-radiative deactivation [67].

The lack of vibrational quenching is more significant for the NIR emitters, since it allows their emission not only in the visible but also in the NIR region. As observed in Figure 8, all compounds show a very wide emission band under UV excitation $\left(\lambda_{\mathrm{ex}}=325 \mathrm{~nm}\right)$, with maxima at ca. $450 \mathrm{~nm}$, corresponding to the above-mentioned ligand fluorescence (caused by $\pi \leftarrow \pi^{*}$ transitions in the aromatic rings). The fact that all compounds are isostructural to each other makes the band very similar for 1, 3, and 4. Moreover, a relatively intense emission is also observed for $\mathbf{1}$ and $\mathbf{4}$ in the NIR region. In particular, a main multiplet is shown at $1060 \mathrm{~nm}$ (structured into two main narrow peaks) in addition to a weak and wider band peaking at ca. $1345 \mathrm{~nm}$ is shown for 1, which is in good agreement with usually observed signals for the $\mathrm{Nd}(\mathrm{III})$-based compounds [68,69]. On its part, compound 4 presents a main manifold located at ca. $1550 \mathrm{~nm}$ with the most intense band sited at $1520 \mathrm{~nm}$, which is an emission attributed to the ${ }^{4} \mathrm{I}_{13 / 2} \rightarrow{ }^{4} \mathrm{I}_{13 / 2}$ transition. The fact that no emission could be found for compound 3 may be explained on the basis of its less discrete energy distribution of the inner ground and excited terms, in such a way that all the charge arriving from the triplet state is easily lost in the form of non-radiative irradiation. 


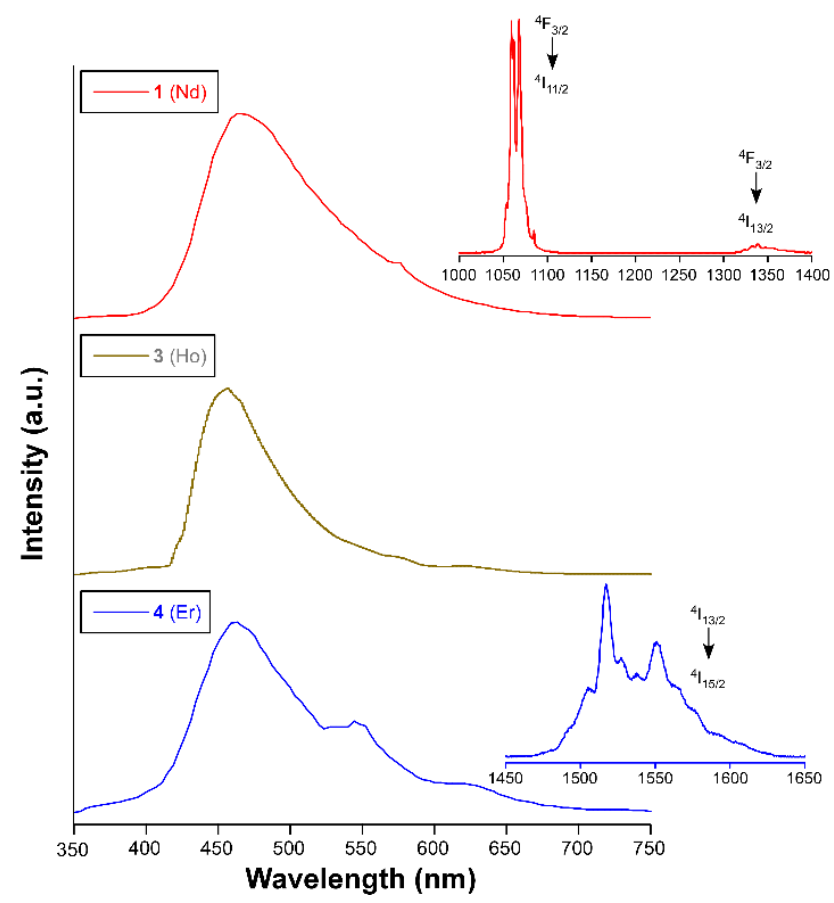

Figure 8. Emission spectra of compounds 1, 3, and 4 recorded at low temperature. The insets aside spectra of $\mathbf{1}$ and $\mathbf{4}$ correspond to the emissions observed in the near-infrared (NIR) spectra.

In view of the strong green emission displayed by compound 2 and the potential porosity contained in its open structure, we decided to explore its luminescence performance by dispersing this sample in different solvents. For these experiments, several dispersions of 2 were prepared by adding $5 \mathrm{mg}$ of the sample into $5 \mathrm{~mL}$ of the corresponding solvent: water, dimethylsulfoxide (DMSO), dimethylformamide (DMF), ethyl acetate (EtAc), chloroform $\left(\mathrm{CH}_{3} \mathrm{Cl}\right)$, dichloromethane $\left(\mathrm{CH}_{2} \mathrm{Cl}_{2}\right)$, diethyl ether, $\left(\mathrm{Et}_{2} \mathrm{O}\right)$ and acetone $(\mathrm{AcO})$. Overall, the spectra measured in this medium is quite similar to that acquired on solid state, although the emission corresponding to the ligand fluorescence ( $L C \lambda_{\mathrm{em}}=450 \mathrm{~nm}$ ) is relatively enlarged with respect to the Tb-based characteristic bands, meaning that the interaction of solvents with the framework (and possibly the effect of the dispersion) somehow interferes in the antenna effect. Moreover, it is observed that the both signals (LC and Tb-based characteristic bands) are progressively weaker across the following sequence (expressed in quenching percentage in regard to emission in water): $\mathrm{H}_{2} \mathrm{O}>$ DMSO $>$ DMF $\sim$ EtAc $>>$ $\mathrm{CH}_{3} \mathrm{Cl}>\mathrm{CH}_{2} \mathrm{Cl}_{2}>\mathrm{Et}_{2} \mathrm{O}>>\mathrm{AcO}$, which approximately agrees with the relative solvent polarity, as previously observed for other PL-MOFs (Figure 9) [70-72]. However, the sample dispersed in $\mathrm{AcO}$ experiences a sudden decrease of the emission intensity, particularly for the $\mathrm{Tb}$-centred bands that are completely null (quenching percentage above $99 \%$ ), whereas the LC emission is weak but visible (quenching percentage of ca. $96 \%$ ). This behavior can be attributed to the specific quenching capacity of the luminescence by the acetone molecules which, possessing methyl groups with $\mathrm{C}-\mathrm{H}$ bonds-well-known quenchers of lanthanide-based luminescent complexes [65,72]—are able to quench the luminescence of the MOF by absorbing the energy accumulated in the excited states of the MOF to enable the non-radiative pathway proceeding through vibrations in the solvent molecules. However, the methyl group is also present in other solvents, meaning that other factors such as the size of the molecules, possibly limiting the entrance in the voids, could be also relevant. 

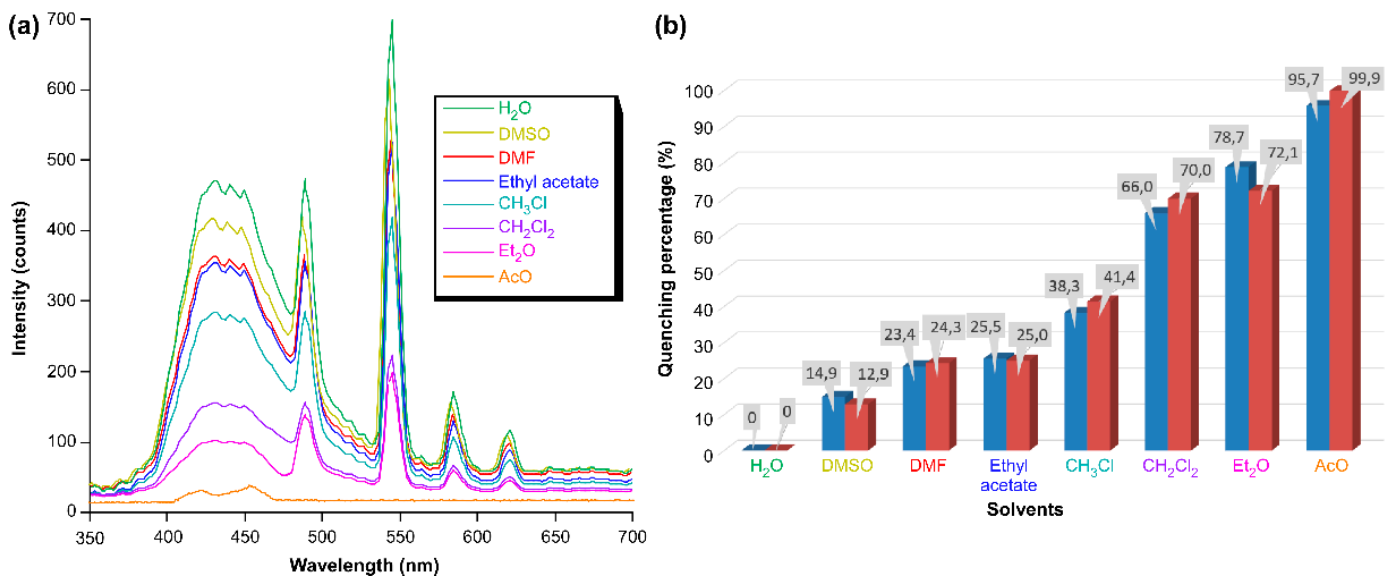

Figure 9. (a) Intensity-dependent emission of compound 2 dispersed under different solvents. (b) Bar chart plot showing the quenching percentage of the LC $\left(\lambda_{\mathrm{em}}=450 \mathrm{~nm}\right.$, blue bars) and Tb-based ${ }^{5} \mathrm{D}_{4} \rightarrow{ }^{7} \mathrm{~F}_{5}$ transition $\left(\lambda_{\mathrm{em}}=548 \mathrm{~nm}\right.$, red bars).

To end up with this characterization, we decided to further explore the mechanism of the quenching process observed in this compound by measuring the decay curves in the dispersions. The results show that overall, the $\mathbf{2} @$ solvent dispersions experiment a significant decrease in their emission longevity, which is an expected behavior considering the collisional quenching occurring in these kinds of dispersions, in which the emission arising from the particles of the luminophore crashes with millions of solvent molecules across the solution [73]. Accordingly, it may be observed that the emission lifetimes are not strictly uniform for all dispersions, but they experience a variable decrease (see Figure S10). In particular, the lifetimes range between values of 260 and $370 \mu$ s, which may be considered different enough to support a dynamic quenching occurring probably as a consequence of the diffusion of the molecules through the pores of the LnOF. However, the absence of emission in the case of acetone, which prevents acquiring a reliable decay curve in this mixture, does not allow further discussion of the mechanism governing that particular quenching.

\section{Materials and Methods}

\subsection{Chemicals}

All reagents were purchased from commercial sources (Merck Life Sciences, Madrid, Spain) and used as received and without further purification.

\subsection{Synthesis of Compounds 1-4}

Compounds 1-4 were obtained by the same solvothermal route through the following procedure. First, $0.0166 \mathrm{mmol}$ of 9,10-anthracenedicarboxylic acid (4.5 mg) and $0.025 \mathrm{mmol}$ of 2,5-diaminoterephthalic acid $(4.5 \mathrm{mg}$ ) were dissolved in $2 \mathrm{~mL}$ of DMF into a glass vial. To this solution, $2 \mathrm{~mL}$ of another DMF solution containing $0.05 \mathrm{mmol}$ of the corresponding lanthanide(III) nitrate salts were added dropwise, observing no precipitation during the process. After sonicating the resulting mixture for two minutes, it was heated in the closed vial at $95{ }^{\circ} \mathrm{C}$ in an oven for $24 \mathrm{~h}$. After this time, and once the mixture was slowly cooled at room temperature, a polycrystalline powder was obtained for all compound except for compound 1, for which single crystals with enough quality for single-crystal X-ray diffraction were collected. Compound $\mathbf{1}$ (yield based on metal: $30 \%$ ): Anal. Calcd. for $\mathrm{C}_{58} \mathrm{H}_{64} \mathrm{~N}_{8} \mathrm{Nd}_{2} \mathrm{O}_{18}: \mathrm{C}, 48.05 ; \mathrm{H}, 4.45 ; \mathrm{N}, 7.73 \%$. Found: $\mathrm{C}, 47.98 ; \mathrm{H}, 4.39 ; \mathrm{N}, 7.78 \%$. Compound 2 (yield based on metal: 35\%): Anal. Calcd. for $\mathrm{C}_{58} \mathrm{H}_{68} \mathrm{~N}_{8} \mathrm{O}_{20} \mathrm{~Tb}_{2}$ : C, 45.98; $\mathrm{H}$, 4.52; N, 7.40\%. Found: C, 46.09; H, 4.42; N, 7.45\%. Compound 3 (yield based on metal: 45\%): Anal. Calcd. for $\mathrm{C}_{58} \mathrm{H}_{68} \mathrm{Ho}_{2} \mathrm{~N}_{8} \mathrm{O}_{20}: \mathrm{C}, 45.62 ; \mathrm{H}, 4.48 ; \mathrm{N}, 7.34 \%$. Found: $\mathrm{C}, 45.78 ; \mathrm{H}, 4.33 ; \mathrm{N}$, 7.28\%. Compound 4 (yield based on metal: $40 \%$ ): Anal. Calcd. for $\mathrm{C}_{58} \mathrm{H}_{68} \mathrm{Er}_{2} \mathrm{~N}_{8} \mathrm{O}_{20}$ : C, 45.48; H, 4.47; N, 7.32\%. Found: C, 45.56; H, 4.38; N, 7.42\%. 


\subsection{Physical Measurements}

Elemental analyses were carried out on a THERMO SCIENTIFIC analyzer model Flash 2000. The infrared spectra measured on powdered samples were recorded on a BRUKER TENSOR 27 FT-IR and OPUS data collection program. PXRD diffractograms were registered in a BRUKER D8 ADVANCE equipment. Magnetic susceptibility measurements were performed on polycrystalline samples of the complexes with a Quantum Design SQUID MPMS-7T susceptometer at an applied magnetic field of $1000 \mathrm{G}$. The susceptibility data were corrected for the diamagnetism estimated from Pascal's Tables [74], the temperature-independent paramagnetism, and the magnetization of the sample holder. Ac measurements were performed on a Physical Property Measurement System-Quantum Design model 6000 magnetometer under a $3.5 \mathrm{G} a c$ field and frequencies ranging from 60 to 10,000 Hz. Photoluminescence spectra were acquired on an Edinburgh Instruments FLS920 spectrometer that is coupled with a close cycle helium cryostat in which the samples are subjected to high vacuum (of ca. $10^{-9} \mathrm{mbar}$ ), which confirms the presence of oxygen or water in the sample holder. The steady-state measurements were done using an IK3552R-G $\mathrm{HeCd}$ continuous laser $(\lambda=325 \mathrm{~nm})$ as an excitation source for the emission spectra or a Müller-Elektronik-Optik SVX1450 Xe lamp for the excitation spectra. The decay curves of compound 2 were acquired with a $\mu \mathrm{F} 900$ microsecond pulsed lamp. The analysis of the fluorescence in the ultraviolet-visible (UV-Vis) region was registered with photomultiplier tube (PMT) coupled to the spectrometer whereas a Hamamatsu NIR-PMT H10330C-75 detector was employed for those compounds emitting in the $\operatorname{NIR}(1,3$, and 4$)$. The overall quantum yield (\%) was measured in solid state for all samples (except for 4-Nd) by means of a Horiba Quanta-' integrating sphere using an Oriel Instruments MS257 lamp as excitation source and an iHR550 spectrometer from Horiba to analyse the emission.

\subsection{Single-Crystal Structure Determination and PXRD Measurements}

The prismatic crystal for $\mathbf{1}$ was mounted on a glass fiber and used for data collection on a Bruker D8 Venture with a photon detector equipped with graphite monochromated MoK $\alpha$ radiation $(\lambda=0.71073 \AA)$. The data reduction was performed with the APEX2 [75] software and corrected for absorption using SADABS [76]. Crystal structures were solved by direct methods using the SHELXT program [77] and refined by full-matrix least-squares on $F^{2}$ including all reflections with the SHELXL-2018/3 program [78] using anisotropic displacement parameters by means of the WINGX crystallographic package [79]. Final $R(F), w R\left(F^{2}\right)$ and goodness-of-fit agreement factors, as well as details on the data collection and analysis can be found in Table 2. CCDC number 1,995,112 contains the supplementary crystallographic data for compounds. These data can be obtained free of charge from The Cambridge Crystallographic Data Centre via www.ccdc.cam.ac.uk/data_request/cif (accessed on 21 February 2021).

The X-ray powder diffractions (XRPD) patterns were collected on a Philips X'PERT powder diffractometer with $\mathrm{Cu} K \alpha$ radiation $(\lambda=1.5418 \AA)$. Indexation of the diffraction profiles was carried out using the FULLPROF program [80], on the basis of the space group and cell parameters found for isostructural compounds by single crystal X-ray diffraction. 
Table 2. Crystallographic data and structure refinement details of compound $\mathbf{1 .}$

\begin{tabular}{cc}
\hline Compound & $\mathbf{1}$ \\
\hline Chemical formula & $\mathrm{C}_{29} \mathrm{H}_{32} \mathrm{~N}_{4} \mathrm{O}_{9} \mathrm{Nd}$ \\
$\mathrm{CCDC}$ & 1995112 \\
$\mathrm{M}\left(\mathrm{g} \mathrm{mol}^{-1}\right)$ & 724.82 \\
$\mathrm{~T}(\mathrm{~K})$ & 100 \\
Cryst. syst. & Triclinic \\
Space group & $P-1$ \\
$a(\AA)$ & $10.4488(6)$ \\
$b(\AA)$ & $11.4058(6)$ \\
$c(\AA)$ & $13.2404(8)$ \\
$\alpha\left(^{\circ}\right)$ & $73.550(2)$ \\
$\beta\left(^{\circ}\right)$ & $86.550(2)$ \\
$\gamma\left({ }^{\circ}\right)$ & $87.175(2)$ \\
$V / \AA^{3}$ & $1509.76(15)$ \\
$Z$ & 2 \\
$\rho / \mathrm{g} \mathrm{cm}^{-3}$ & 1.594 \\
$\mu / \mathrm{mm}^{-1}$ & 1.778 \\
$\mathrm{R}_{1}{ }^{\mathrm{a}} / \mathrm{wR}_{2}{ }^{\mathrm{b}}[\mathrm{I}>2 \sigma(\mathrm{I})]$ & $0.0620 / 0.1411$ \\
$\mathrm{R}_{1}{ }^{\mathrm{a}} / \mathrm{wR}_{2}{ }^{\mathrm{b}}[\mathrm{all}$ data] & $0.0816 / 0.1520$ \\
\hline
\end{tabular}

${ }^{\mathrm{a}} R_{1}=\mathrm{S}|| \mathrm{F}_{\mathrm{o}}|-| \mathrm{F}_{\mathrm{c}}|| / \mathrm{S}\left|\mathrm{F}_{\mathrm{o}}\right|{ }^{\mathrm{b}} w R_{2}=\left\{\mathrm{S}\left[w\left(F_{0}{ }^{2}-{F_{c}}^{2}\right)^{2}\right] / \mathrm{S}\left[w\left(F_{0}{ }^{2}\right)^{2}\right]\right\}^{\frac{1}{2}} ;$ where $\mathrm{w}=1 /\left[\sigma^{2}\left(\mathrm{~F}_{0}{ }^{2}\right)+(\mathrm{aP})^{2}+\mathrm{bP}\right]$ and $\mathrm{P}$ $=\left(\max \left(\mathrm{F}_{0}^{2}, 0\right)+2 \mathrm{Fc}^{2}\right) / 3$ with $\mathrm{a}=0.0600$ and $\mathrm{b}=12.7562$.

\section{Conclusions}

In the present study, two related 3D LnOFs are chemically and structurally characterized to show that they present isoreticular frameworks of pcu topology but distinct chemical formula due to the different coordination shown by the carboxylate aromatic ligands to the selected lanthanide(III) ions on the basis of their ion size. In particular, frameworks of $\mathbf{1}$ and 2-4 differ in the bridging coordination pattern shown by the $\left(\mathrm{NH}_{2}\right)_{2}-$ $\mathrm{bdc}^{2-}$ ligand within the dimeric paddle-wheel shaped building unit, being respectively $\mu-\kappa^{2} \mathrm{O}, \mathrm{O}^{\prime}: \kappa \mathrm{O}$ and $\mu-\mathrm{kO}: \mathrm{k} \mathrm{O}^{\prime}$. The magnetic behavior of these compounds is dominated by the spin-orbit coupling of lanthanide(III) ions, which are found to be practically isolated in the framework as corroborated by the DFT computed values of the magnetic exchange interactions occurring within the dinuclear building units. In this sense, the computational study suggests that the net weak interaction proceeds through a ferromagnetic coupling derived from the countercomplementarity of the coexisting carboxylate bridges of $\left(\mathrm{NH}_{2}\right)_{2}-\mathrm{bdc}^{2-}$ and ant ${ }^{2-}$ ligands characterized for rendering antiferromagnetic couplings. Compounds 1, 2, and 4 show characteristic emissions centred on their corresponding lanthanide(III) ions sited in the visible (for $\mathbf{1}$ ) and NIR (for $\mathbf{2}$ and $\mathbf{4}$ ) regions. The bright green emission afforded by compound $\mathbf{1}$, featuring a long-lived luminescence of nearly a millisecond, shows a solvent-dependent behavior in response to the interaction of the $\mathrm{Tb}-\mathrm{OF}$ with the solvent medium. Compound $\mathbf{1}$ experiments a complete turn-off in acetone, which awakens its interest for further studies of each sensing activity. The turning-off response of the solvent-dependent luminescence of $\mathbf{1}$ seems to proceed through a dynamic quenching according to the variability of emission lifetimes measured in the solvent dispersions.

Supplementary Materials: The following are available online at https:/ / www.mdpi.com/2312-748 1/7/3/41/s1, Figure S1: Pattern-matching analysis and crystalline parameters of the polycrystalline sample of compound 2, Figure S2: Pattern-matching analysis and crystalline parameters of the polycrystalline sample of compound 3, Figure S3: Pattern-matching analysis and crystalline parameters of the polycrystalline sample of compound 4, Figure S4: Captures of the 3D framework of compound 1 showing the voids present that are occupied by lattice DMF molecules. Two different views are shown: along b axis (left) and along a axis (right). $\mathrm{N}=$ blue, $\mathrm{O}=$ red, $\mathrm{C}=$ gray, $\mathrm{Nd}=$ green, Figure S5: Captures of the 3D framework of compounds 2-4 showing the connected voids present. Two different views are shown: along $c$ axis (left) and along $a$ axis (right). $\mathrm{N}=$ blue, $\mathrm{O}=$ red, $\mathrm{C}=$ gray, Tb, Ho or Er = green, Figure S6: Temperature dependence of the in-phase (top) and out-of-phase (bottom) 
components of the ac susceptibility for 4 under an external field of 1000 Oe (the susceptibility values are given per $\operatorname{Er}(\mathrm{III})$ ion, Figure S7: Cole-Cole plots under 1000 Oe external field for $\mathbf{1}$. Solid lines represent the best fits to the generalized Debye model, Figure S8: Excitation spectrum of compound 2 measured at room temperature at $\lambda_{\mathrm{em}}=548 \mathrm{~nm}$, Figure S9: Excitation spectrum of compound 2 measured at room temperature at $\lambda_{\mathrm{em}}=548 \mathrm{~nm}$, Figure S10: Decay curves of compound 2 acquired on dispersions of different solvents (see specified conditions), Table S1: Data of pattern-matching refinement of compound 2, Table S2: Data of pattern-matching refinement of compound 3, Table S3: Data of pattern-matching refinement of compound 4, Table S4: Continuous Shape Measures Calculations for herein described compound 1, and previously reported $\left\{\left[\mathrm{Nd}(\mathrm{ant})_{1.5}(\mathrm{DMF})_{2}\right] \cdot(\mathrm{DMF})\right\}_{\mathrm{n}}$, $\left\{\left[\mathrm{Dy}(\mathrm{ant})_{1.5}(\mathrm{DMF})_{2}\right] \cdot(\mathrm{DMF})\right\}_{\mathrm{n}}$ and $\left\{\left[\mathrm{Dy}_{2}(\mathrm{ant})_{2}\left(\left(\mathrm{NH}_{2}\right)_{2} \text {-bdc }\right)(\mathrm{DMF})_{4}\right] \cdot 2 \mathrm{DMF} \cdot 2 \mathrm{H}_{2} \mathrm{O}\right\}_{\mathrm{n}}$, Table S5: Continuous Shape Measures Calculations for the isostructural Dy-based analogue of compounds 2-4 due to the lack of single crystals of these specimens. The $\mathrm{Tb}(2), \mathrm{Ho}(3)$ and $\mathrm{Er}$ (4) compounds are expected to have similar coordination environments to that of Dy in both materials.

Author Contributions: Conceptualization, A.R.-D.; methodology, S.R. and A.D.P.; software, I.O. and J.C.; validation, A.S.-C. and J.M.S.; formal analysis, J.C. and I.O.; investigation, A.D.P. and A.R.-D.; resources, J.Á.G. and A.R.-D.; data curation, I.O., J.Á.G. and J.C.; writing-original draft preparation, I.O., J.C. and A.R.-D.; writing-review and editing, J.C.; visualization, I.O., S.R. and A.S.-C.; supervision, A.R.-D.; project administration, J.C. and A.R.-D.; funding acquisition, J.M.S., J.C. and A.R.-D. All authors have read and agreed to the published version of the manuscript.

Funding: This work was supported by the Spanish Ministry of Science, Innovation and Universities (MCIU/AEI/FEDER, UE) (PGC2018-102052-A-C22, PGC2018-102052-B-C21, PID2019-108028GBC21), Junta de Andalucía (FQM-394), Gobierno Vasco/Eusko Jaurlaritza (IT1005-16, IT1291-19) and University of the Basque Country (UPV/EHU) (GIU 17/13). S.R. acknowledge the Juan de la Cierva Incorporación Fellowship (grant agreement $n^{\circ}$. IJC2019-038894-I). The authors thank for technical and human support provided by SGIker of UPV/EHU and European funding (ERDF and ESF).

Institutional Review Board Statement: Not applicable.

Informed Consent Statement: Not applicable.

Acknowledgments: The "Centro de Instrumentación Científica" of University of Granada is greatly acknowledged for its human and technical support regarding many techniques employed in this work.

Conflicts of Interest: The authors declare no conflict of interest.

\section{References}

1. Meek, S.T.; Greathouse, J.A.; Allendorf, M.D. Metal-Organic Frameworks: A Rapidly Growing Class of Versatile Nanoporous Materials. Adv. Mater. 2011, 23, 249-267. [CrossRef]

2. Cheetham, A.K.; Rao, C.N.R. There's Room in the Middle. Science 2007, 318, 58-59. [CrossRef] [PubMed]

3. Batten, S.R.; Champness, N.R.; Chen, X.-M.; Garcia-Martinez, J.; Kitagawa, S.; Öhrström, L.; O'Keeffe, M.; Suh, M.P.; Reedijk, J. Terminology of metal-organic frameworks and coordination polymers (IUPAC Recommendations 2013). Pure Appl. Chem. 2013, 85, 1715-1724. [CrossRef]

4. Yaghi, O.M.; O’Keeffe, M.; Ockwig, N.W.; Chae, H.K.; Eddaoudi, M.; Kim, J. Reticular synthesis and the design of new materials. Nat. Cell Biol. 2003, 423, 705-714. [CrossRef] [PubMed]

5. Zhang, M.; Bosch, M.; Iii, T.G.; Zhou, H.-C. Rational design of metal-organic frameworks with anticipated porosities and functionalities. CrystEngComm 2014, 16, 4069-4083. [CrossRef]

6. Heine, J.; Müller-Buschbaum, K. Engineering metal-based luminescence in coordination polymers and metal-organic frameworks. Chem. Soc. Rev. 2013, 42, 9232-9242. [CrossRef]

7. Bünzli, J.-C.G. On the design of highly luminescent lanthanide complexes. Coord. Chem. Rev. 2015, 293-294, 19-47. [CrossRef]

8. Qiu, S.; Xue, M.; Zhu, G. Metal-organic framework membranes: from synthesis to separation application. Chem. Soc. Rev. 2014, 43, 6116-6140. [CrossRef]

9. Voorde, B.V.D.; Bueken, B.; Denayer, J.; Vos, D. De Adsorptive separation on metal-organic frameworks in the liquid phase. Chem. Soc. Rev. 2014, 43, 5766-5788. [CrossRef]

10. Barea, E.; Montoro, C.; Navarro, J.A.R. Toxic gas removal-Metal-organic frameworks for the capture and degradation of toxic gases and vapours. Chem. Soc. Rev. 2014, 43, 5419-5430. [CrossRef]

11. Saha, S.; Chandra, S.; Garai, B.; Banerjee, R. Carbon dioxide capture by metal organic frameworks. Indian J. Chem. 2012, 51, 1223-1230. 
12. Mendiratta, S.; Lee, C.-H.; Usman, M.; Lu, K.-L. Metal-organic frameworks for electronics: Emerging second order nonlinear optical and dielectric materials. Sci. Technol. Adv. Mater. 2015, 16, 054204. [CrossRef] [PubMed]

13. Stavila, V.; Talin, A.A.; Allendorf, M.D. MOF-based electronic and opto-electronic devices. Chem. Soc. Rev. 2014, 43, 5994-6010. [CrossRef] [PubMed]

14. Minguez Espallargas, G.M.; Coronado, E. Magnetic functionalities in MOFs: From the framework to the pore. Chem. Soc. Rev. 2018, 47, 533-557. [CrossRef] [PubMed]

15. Saraci, F.; Quezada-Novoa, V.; Donnarumma, P.R.; Howarth, A.J. Rare-earth metal-organic frameworks: From structure to applications. Chem. Soc. Rev. 2020, 49, 7949-7977. [CrossRef] [PubMed]

16. Liu, C.M.; Zhang, D.Q.; Hao, X.; Zhu, D. Ben Luminescence and slow magnetic relaxation of isostructural 2D lanthanide metal-organic frameworks derived from both nicotinate N-oxide and glutarate. RSC Adv. 2015, 5, 92980-92987. [CrossRef]

17. Luo, L.-L.; Qu, X.-L.; Li, Z.; Li, X.; Sun, H.-L. Isostructural lanthanide-based metal-organic frameworks: Structure, photoluminescence and magnetic properties. Dalton Trans. 2017, 47, 925-934. [CrossRef]

18. García-García, A.; Zabala-Lekuona, A.; Goñi-Cárdenas, A.; Cepeda, J.; Seco, J.M.; Salinas-Castillo, A.; ChoquesilloLazarte, D.; Rodríguez-Diéguez, A. Magnetic and luminescent properties of isostructural 2d coordination polymers based on 2-pyrimidinecarboxylate and lanthanide ions. Crystals 2020, 10, 571. [CrossRef]

19. Binnemans, K. Lanthanide-Based Luminescent Hybrid Materials. Chem. Rev. 2009, 109, 4283-4374. [CrossRef]

20. Woodruff, D.N.; Winpenny, R.E.P.; Layfield, R.A. Lanthanide Single-Molecule Magnets. Chem. Rev. 2013, 113, 5110-5148. [CrossRef]

21. Kuznetsova, A.; Matveevskaya, V.; Pavlov, D.; Yakunenkov, A.; Potapov, A. Coordination Polymers Based on Highly Emissive Ligands: Synthesis and Functional Properties. Materials 2020, 13, 2699. [CrossRef] [PubMed]

22. Frost, J.M.; Harriman, K.L.M.; Murugesu, M. The rise of 3-d single-ion magnets in molecular magnetism: Towards materials from molecules? Chem. Sci. 2016, 7, 2470-2491. [CrossRef]

23. Craig, G.A.; Murrie, M. 3d single-ion magnets. Chem. Soc. Rev. 2015, 44, 2135-2147. [CrossRef]

24. Jia, J.-H.; Li, Q.-W.; Chen, Y.-C.; Liu, J.-L.; Tong, M.-L. Luminescent single-molecule magnets based on lanthanides: Design strategies, recent advances and magneto-luminescent studies. Coord. Chem. Rev. 2019, 378, 365-381. [CrossRef]

25. Bi, Y.; Chen, C.; Zhao, Y.-F.; Zhang, Y.-Q.; Jiang, S.-D.; Wang, B.-W.; Han, J.-B.; Sun, J.-L.; Bian, Z.-Q.; Wang, Z.-M.; et al. Thermostability and photoluminescence of Dy(iii) single-molecule magnets under a magnetic field. Chem. Sci. 2016, 7, 5020-5031. [CrossRef]

26. Almeida Paz, F.A.A.; Klinowski, J.; Vilela, S.M.F.; Tomé, J.P.C.; Cavaleiro, J.A.S.; Rocha, J. Ligand design for functional metalorganic frameworks. Chem. Soc. Rev. 2011, 41, 1088-1110. [CrossRef]

27. Baldoví, J.J.; Coronado, E.; Gaita-Ariño, A.; Gamer, C.; Giménez-Marqués, M.; Minguez Espallargas, G.M. A SIM-MOF: ThreeDimensional Organisation of Single-Ion Magnets with Anion-Exchange Capabilities. Chem. Eur. J. 2014, 20, 10695-10702. [CrossRef] [PubMed]

28. Sessoli, R.; Powell, A.K. Strategies towards single molecule magnets based on lanthanide ions. Coord. Chem. Rev. 2009, 253, 2328-2341. [CrossRef]

29. Guo, F.-S.; Day, B.M.; Chen, Y.-C.; Tong, M.-L.; Mansikkamäki, A.; Layfield, R.A. Magnetic hysteresis up to 80 kelvin in a dysprosium metallocene single-molecule magnet. Science 2018, 362, 1400-1403. [CrossRef]

30. Mao, J.-G. Structures and luminescent properties of lanthanide phosphonates. Co-ord. Chem. Rev. 2007, 251, 1493-1520. [CrossRef]

31. Barry, D.E.; Caffrey, D.F.; Gunnlaugsson, T. Lanthanide-directed synthesis of luminescent self-assembly supramolecular structures and mechanically bonded systems from acyclic coordinating organic ligands. Chem. Soc. Rev. 2016, 45, 3244-3274. [CrossRef] [PubMed]

32. Huizi-Rayo, U.; Zabala-Lekuona, A.; Terenzi, A.; Cruz, C.M.; Cuerva, J.M.; Rodríguez-Diéguez, A.; García, J.A.; Seco, J.M.; Sebastian, E.S.; Cepeda, J. Influence of thermally induced structural transformations on the magnetic and luminescence properties of tartrate-based chiral lanthanide organic-frameworks. J. Mater. Chem. C 2020, 8, 8243-8256. [CrossRef]

33. Bünzli, J.-C.G.; Piguet, C. Taking advantage of luminescent lanthanide ions. Chem. Soc. Rev. 2005, 34, 1048-1077. [CrossRef] [PubMed]

34. Kreno, L.E.; Leong, K.; Farha, O.K.; Allendorf, M.; Van Duyne, R.P.; Hupp, J.T. Metal-Organic Framework Materials as Chemical Sensors. Chem. Rev. 2012, 112, 1105-1125. [CrossRef]

35. Zhao, S.-N.; Wang, G.; Poelman, D.; Voort, P.V.D. Luminescent Lanthanide MOFs: A Unique Platform for Chemical Sensing. Materials 2018, 11, 572. [CrossRef]

36. Calahorro, A.J.; Oyarzabal, I.; Fernández, B.; Seco, J.M.; Tian, T.; Fairen-Jimenez, D.; Colacio, E.; Rodríguez-Diéguez, A. Rare earth anthracenedicarboxylate metal-organic frameworks: Slow relaxation of magnetization of Nd3+, Gd3+, Dy3+, Er3+ and Yb3+ based materials. Dalton Trans. 2015, 45, 591-598. [CrossRef]

37. Oyarzabal, I.; Fernández, B.; Cepeda, J.; Gómez-Ruiz, S.; Calahorro, A.J.; Seco, J.M.; Rodríguez-Diéguez, A. Slow relaxation of magnetization in 3D-MOFs based on dysprosium dinuclear entities bridged by dicarboxylic linkers. CrystEngComm 2016, 18, 3055-3063. [CrossRef]

38. Cepeda, J.; Balda, R.; Beobide, G.; Castillo, O.; Fernández, J.; Luque, A.; Pérez-Yáñez, S.; Román, P. Synthetic Control to Achieve Lanthanide(III)/Pyrimidine-4,6-dicarboxylate Compounds by Preventing Oxalate Formation: Structural, Magnetic, and Luminescent Properties. Inorg. Chem. 2012, 51, 7875-7888. [CrossRef] 
39. Zabala-Lekuona, A.; Cepeda, J.; Oyarzabal, I.; Rodríguez-Diéguez, A.; García, J.A.; Seco, J.M.; Colacio, E. Rational design of triple-bridged dinuclear ZnIILnIII-based complexes: A structural, magnetic and luminescence study. CrystEngComm 2017, 19, 256-264. [CrossRef]

40. Cepeda, J.; Pérez-Yáñez, S.; Beobide, G.; Castillo, O.; García, J.Á.; Luque, A. Photoluminescence Modulation in Lanthanide(III)/ Pyrazine-2,5-dicarboxylato/Nitrato Frameworks. Eur. J. Inorg. Chem. 2015, 2015, 4318-4328. [CrossRef]

41. Alvarez, S.; Avnir, D.; Llunell, M.; Pinsky, M. Continuous symmetry maps and shape classification. New J. Chem. 2002, 26, 996-1009. [CrossRef]

42. Blatov, V.A.; Shevchenko, A.P.; Proserpio, D.M. Applied Topological Analysis of Crystal Structures with the Program Package ToposPro. Cryst. Growth Des. 2014, 14, 3576-3586. [CrossRef]

43. Blatov, V.A.; O'Keeffe, M.; Proserpio, D.M. Vertex-, face-, point-, Schläfli-, and Delaney-symbols in nets, polyhedra and tilings: Recommended terminology. CrystEngComm 2009, 12, 44-48. [CrossRef]

44. Alvarez, S. Polyhedra in (inorganic) chemistry. Dalton Trans. 2005, 13, 2209-2233. [CrossRef] [PubMed]

45. Sorace, L.; Benelli, C.; Gatteschi, D. Lanthanides in molecular magnetism: Old tools in a new field. Chem. Soc. Rev. 2011, 40, 3092-3104. [CrossRef] [PubMed]

46. Ruiz, J.; Mota, A.J.; Rodriguez-Dieguez, A.; Oyarzabal, I.; Seco, J.M.; Colacio, E. Rational design of ferromagnetic coupled diphenoxocarboxylate triply bridged dinuclear nickel(ii) complexes: Orbital countercomplementarity of the bridging ligands. Dalton Trans. 2012, 41, 14265-14273. [CrossRef] [PubMed]

47. McKee, V.; Zvagulis, M.; Reed, C.A. ChemInform Abstract: Further insight into magnetostructural corelations in binuclear copper(II) species related to methemocyanin: X-ray crystal structure of a 1,2- $\mu$-nitro complex. Inorg. Chem. Inf. 1985, 16, 2914-2919. [CrossRef]

48. Nishida, Y.; Kida, S. Crystal structures and magnetism of binuclear copper(II) complexes with alkoxide bridges. Importance of orbital complementarity in spin coupling through two different bridging groups. J. Chem. Soc. Dalton Trans. 1986, 2633-2640. [CrossRef]

49. Pérez-Yáñez, S.; Castillo, O.; Cepeda, J.; García-Terán, J.P.; Luque, A.; Román, P. Analysis of the interaction between adenine nucleobase and metal-malonato complexes. Eur. J. Inorg. Chem. 2009. [CrossRef]

50. Rinehart, J.D.; Long, J.R. Slow magnetic relaxation in homoleptic trispyrazolylborate complexes of neodymium(iii) and uranium(iii). Dalton Trans. 2012, 41, 13572-13574. [CrossRef]

51. Gómez-Coca, S.; Urtizberea, A.; Cremades, E.; Alonso, P.J.; Camón, A.; Ruiz, E.; Luis, F. Origin of slow magnetic relaxation in Kramers ions with non-uniaxial anisotropy. Nat. Commun. 2014, 5, 4300. [CrossRef] [PubMed]

52. Pinsky, M.; Avnir, D. Continuous Symmetry Measures. The Classical Polyhedra. Inorg. Chem. 1998, 37, 5575-5582. [CrossRef] [PubMed]

53. Ruiz-Martínez, A.; Casanova, D.; Alvarez, S. Polyhedral structures with an odd number of vertices: Nine-atom clusters and supramolecular architectures. J. Chem. Soc. Dalt. Trans. 2008, 19, 2583-2591. [CrossRef] [PubMed]

54. Costes, J.P.; Titos-Padilla, S.; Oyarzabal, I.; Gupta, T.; Duhayon, C.; Rajaraman, G.; Colacio, E. Effect of Ligand Substitution around the DyIII on the SMM Properties of Dual-Luminescent Zn-Dy and Zn-Dy-Zn Complexes with Large Anisotropy Energy Barriers: A Combined Theoretical and Experimental Magnetostructural Study. Inorg. Chem. 2016, 55, 4428-4440. [CrossRef] [PubMed]

55. Rinehart, J.D.; Long, J.R. Exploiting single-ion anisotropy in the design of f-element single-molecule magnets. Chem. Sci. 2011, 2 , 2078-2085. [CrossRef]

56. Evans, R.C.; Douglas, P.; Winscom, C.J. Coordination complexes exhibiting room-temperature phosphorescence: Evaluation of their suitability as triplet emitters in organic light emitting diodes. Co-ord. Chem. Rev. 2006, 250, 2093-2126. [CrossRef]

57. San Sebastian, E.S.; Rodríguez-Diéguez, A.; Seco, J.M.; Cepeda, J. Coordination Polymers with Intriguing Photoluminescence Behavior: The Promising Avenue for Greatest Long-Lasting Phosphors. Eur. J. Inorg. Chem. 2018, 2018, 2155-2174. [CrossRef]

58. Liu, Q.-D.; Wang, R.; Wang, S. Blue phosphorescent Zn(ii) and orange phosphorescent Pt(ii) complexes of 4,4'-diphenyl-6,6'dimethyl-2,2'-bipyrimidine. Dalton Trans. 2004, 35, 2073-2079. [CrossRef]

59. Rocha, J.; Brites, C.D.S.; Carlos, L.D. Lanthanide Organic Framework Luminescent Thermometers. Chem. Eur. J. 2016, 22, 14782-14795. [CrossRef]

60. Hagan, A.K.; Zuchner, T. Lanthanide-based time-resolved luminescence immunoassays. Anal. Bioanal. Chem. 2011, 400, 2847-2864. [CrossRef]

61. Kim, N.; Son, S.-H. Development of Dissociation-Enhanced Lanthanide Fluoroimmunoassay for Measuring Leptin. J. Fluoresc. 2016, 26, 1715-1721. [CrossRef] [PubMed]

62. Dotsenko, A.V.; Glebov, L.B.; Tsekhomsky, A.V.; Kokorina, V.F. Phosphor Handbook, 2nd ed.; CRC Press: Boca Raton, FL, USA, 2003; Volume 23.

63. Soares-Santos, P.C.R.; Cunha-Silva, L.; Paz, F.A.A.; Ferreira, R.A.S.; Rocha, J.; Carlos, L.D.; Nogueira, H.I.S. Photoluminescent Lanthanide-Organic Bilayer Networks with 2,3-Pyrazinedicarboxylate and Oxalate. Inorg. Chem. 2010, 49, 3428-3440. [CrossRef] [PubMed]

64. Cepeda, J.; Pérez-Yáñez, S.; Beobide, G.; Castillo, O.; García, J. Ángel; Lanchas, M.; Luque, A. Enhancing luminescence properties of lanthanide(iii)/pyrimidine-4,6-dicarboxylato system by solvent-free approach. Dalton Trans. 2015, 44, 6972-6986. [CrossRef]

65. De Bettencourt-Dias, A.; Barber, P.S.; Viswanathan, S.; De Lill, D.T.; Rollett, A.; Ling, G.; Altun, S. Para-Derivatized Pybox Ligands as Sensitizers in Highly Luminescent Ln(III) Complexes. Inorg. Chem. 2010, 49, 8848-8861. [CrossRef] [PubMed] 
66. Jüstel, T.; Nikol, H.; Ronda, C. New Developments in the Field of Luminescent Materials for Lighting and Displays. Angew. Chem. 1998, 37, 3084-3103. [CrossRef]

67. Allendorf, M.D.; Bauer, C.A.; Bhakta, R.K.; Houk, R.J.T. Luminescent metal-organic frameworks. Chem. Soc. Rev. 2009, 38, 1330-1352. [CrossRef]

68. Ruiz-Muelle, A.B.; García-García, A.; García-Valdivia, A.A.; Oyarzabal, I.; Cepeda, J.; Seco, J.M.; Colacio, E.; RodríguezDiéguez, A.; Fernández, I. Design and synthesis of a family of 1D-lanthanide-coordination polymers showing luminescence and slow relaxation of the magnetization. Dalton Trans. 2018, 47, 12783-12794. [CrossRef]

69. Eliseeva, S.V.; Bünzli, J.-C.G. Rare earths: Jewels for functional materials of the future. New J. Chem. 2011, 35, 1165-1176. [CrossRef]

70. Pajuelo-Corral, O.; Rodríguez-Diéguez, A.; Beobide, G.; Pérez-Yáñez, S.; García, J.A.; San Sebastian, E.S.; Seco, J.M.; Cepeda, J. Alkaline-earth and aminonicotinate based coordination polymers with combined fluorescence/long-lasting phosphorescence and metal ion sensing response. J. Mater. Chem. C 2019, 7, 6997-7012. [CrossRef]

71. Chests, C.A.; Avila, V.; Soltermann, A.T.; Previtali, C.M.; Cosa, J.J.; Crystallb, P.B.; Phillipsb, D. Solvent effects on the fluorescence quenching rate constant of an intramolecular exciplex by poly (chlorobenzenes ). J. Chem. Soc. Faraday Trans. 1996, 92, 3327-3332. [CrossRef]

72. Eliseeva, S.V.; Pleshkov, D.N.; Lyssenko, K.A.; Lepnev, L.S.; Bünzli, J.-C.G.; Kuzmina, N.P. Highly Luminescent and Triboluminescent Coordination Polymers Assembled from Lanthanide $\beta$-Diketonates and Aromatic BidentateO-Donor Ligands. Inorg. Chem. 2010, 49, 9300-9311. [CrossRef]

73. Lakowicz, J.R. General Features of Protein Fluorescence; Springer: Boston, MA, USA, 2006.

74. Earnshaw, A. Introduction to Magnetochemistry; Academic Press: London, UK, 1968.

75. Bruker AXS Inc. APEX2 User Manual. 2004. Available online: http://xraysweb.lbl.gov/bl1131/1131website/doc/brukerapex2 \%20user\%20manual.pdf (accessed on 21 February 2021).

76. Sheldrick, G.M. SADABS 1996, Program for Empirical Adsorption Correction; University of Göttingen: Göttingen, Germany, $1996 ;$ p. 467.

77. Sheldrick, G.M. A short history of SHELX. Acta Cryst. 2008, 64, 112-122. [CrossRef] [PubMed]

78. Sheldrick, G.M. Crystal structure refinement with SHELXL. Acta Cryst. 2015, 71, 3-8.

79. Farrugia, L.J. WinGX and ORTEP for Windows: An update. J. Appl. Crystallogr. 2012, 45, 849-854. [CrossRef]

80. Rodríguez-Carvajal, J. FULLPROF 2000; Version 2.5d; Laboratoire Léon Brillouin (CEA-CNRS), Centre d'Études deSaclay: Gif sur Yvette Cedex, France, 2003. 